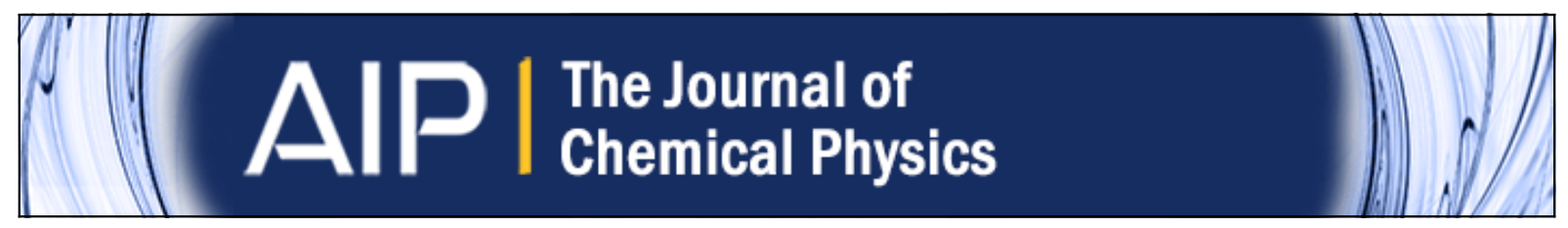

Conformers, infrared spectrum, UV-induced photochemistry, and near-IR-induced generation of two rare conformers of matrix-isolated phenylglycine

Ana Borba, Andrea Gómez-Zavaglia, and Rui Fausto

Citation: The Journal of Chemical Physics 141, 154306 (2014); doi: 10.1063/1.4897526

View online: http://dx.doi.org/10.1063/1.4897526

View Table of Contents: http://scitation.aip.org/content/aip/journal/jcp/141/15?ver=pdfcov

Published by the AIP Publishing

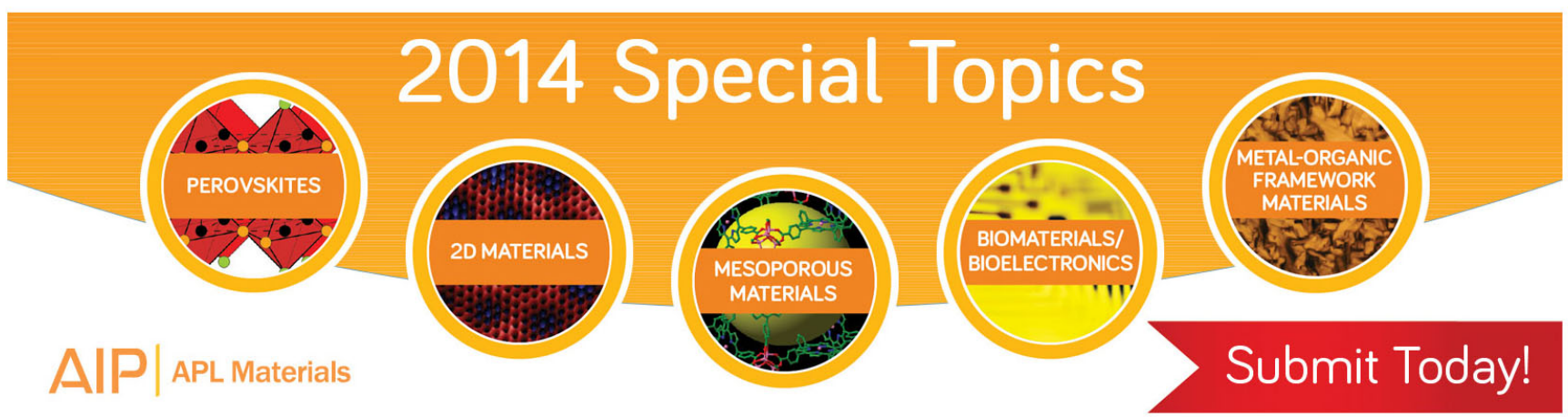




\title{
Conformers, infrared spectrum, UV-induced photochemistry, and near-IR-induced generation of two rare conformers of matrix-isolated phenylglycine
}

\author{
Ana Borba, ${ }^{1, \text { a) }}$ Andrea Gómez-Zavaglia, ${ }^{1,2}$ and Rui Fausto ${ }^{1}$ \\ ${ }^{1}$ Department of Chemistry, University of Coimbra, Coimbra P-3004-535, Portugal \\ ${ }^{2}$ Center for Research and Development in Food Cryotechnology, (Conicet La Plata, UNLP) \\ RA-1900, Argentina
}

(Received 8 August 2014; accepted 26 September 2014; published online 17 October 2014)

\begin{abstract}
The conformational space of $\alpha$-phenylglycine (PG) have been investigated theoretically at both the DFT/B3LYP/6-311++G(d,p) and MP2/6-311++G(d,p) levels of approximation. Seventeen different minima were found on the investigated potential energy surfaces, which are characterized by different dominant intramolecular interactions: type I conformers are stabilized by hydrogen bonds of the type $\mathrm{N}-\mathrm{H} \cdots \mathrm{O}=\mathrm{C}$, type II by a strong $\mathrm{O}-\mathrm{H} \cdots \mathrm{N}$ hydrogen bond, type III by weak $\mathrm{N}-\mathrm{H} \cdots \mathrm{O}-\mathrm{H}$ hydrogen bonds, and type IV by a $\mathrm{C}=\mathrm{O} \cdots \mathrm{H}-\mathrm{C}$ contact. The calculations indicate also that entropic effects are relevant in determining the equilibrium populations of the conformers of PG in the gas phase, in particular in the case of conformers of type II, where the strong intramolecular $\mathrm{O}-\mathrm{H} \cdots \mathrm{N}$ hydrogen bond considerably diminishes entropy by reducing the conformational mobility of the molecule. In consonance with the relative energies of the conformers and barriers for conformational interconversion, only 3 conformers of PG were observed for the compound isolated in cryogenic $\mathrm{Ar}, \mathrm{Xe}$, and $\mathrm{N}_{2}$ matrices: the conformational ground state (ICa), and forms ICc and IITa. All other significantly populated conformers existing in the gas phase prior to deposition convert either to conformer ICa or to conformer ICc during matrix deposition. The experimental observation of ICc had never been achieved hitherto. Narrowband near-IR irradiation of the first overtone of $\nu \mathrm{OH}$ vibrational mode of ICa and ICc in nitrogen matrices (at 6910 and $6930 \mathrm{~cm}^{-1}$, respectively) led to selective generation of two additional conformers of high-energy, ITc and ITa, respectively, which were also observed experimentally for the first time. In addition, these experiments also provided the key information for the detailed vibrational characterization of the 3 conformers initially present in the matrices. On the other hand, UV irradiation $(\lambda=255 \mathrm{~nm})$ of PG isolated in a xenon matrix revealed that PG undergoes facile photofragmentation through two photochemical pathways that are favored for different initial conformations of the reactant: (a) decarboxylation, leading to $\mathrm{CO}_{2}$ plus benzylamine (the dominant photofragmentation channel in PG cis-COOH conformers ICa and ICc) and (b) decarbonylation, with generation of $\mathrm{CO}$ plus benzonitrile, $\mathrm{H}_{2} \mathrm{O}$ and $\mathrm{H}_{2}$ (prevalent in the case of the trans-COOH conformer, IITa). @ 2014 AIP Publishing LLC. [http://dx.doi.org/10.1063/1.4897526]
\end{abstract}

\section{INTRODUCTION}

$\alpha$-Phenylglycine (or $\alpha$-aminophenylacetic acid: PG; Scheme 1) is an unnatural amino acid, with reported genotoxic activity ${ }^{1,2}$ and participation in antitumor and neuropathic drug synthesis. ${ }^{3}$

Unnatural amino acids are matter of increasing interest in different domains. They can be incorporated as new building blocks into the genetic codes of both prokaryotic and eukaryotic organisms to facilitate studies of protein structure and function. Over 30 unnatural amino acids with modified side chains have been genetically encoded in response to unique triplet and quadruplet codons. ${ }^{4}$ In addition, these compounds are used as scaffolds to orient unnatural functional groups or effectors. ${ }^{5}$

Like in natural amino acids, conformational and enantiomeric isomerism determines the physical, chemical,

\footnotetext{
a) Author to whom correspondence should be addressed. Electronic mail: anaborba@ci.uc.pt
}

and biological properties of unnatural aminoacids. Their rotational flexibility allows, in general, the existence of several significantly populated conformational forms, whose specific geometries are determined by the balance between stabilizing effects (e.g., hyperconjugation, dispersion forces, and intramolecular H-bonds) and destabilizing steric effects, including lone electron pairs repulsions. The combination

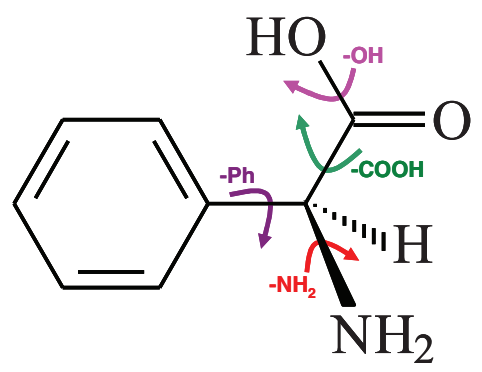

SCHEME 1. Schematic representation of the PG molecule, indicating its four rotational axes. 
of all these factors complicates the structural analysis of these molecules if no systematic strategies of investigation are adopted. In addition, since the molecular form of amino acids, existing in gas phase or for the isolated molecule in a cryogenic matrix, ${ }^{6-13}$ is the species resembling more the amino acids in a peptide (instead of the zwitterionic form), the study of the conformational space of this form is particularly relevant.

PG is indeed a rather flexible molecule because it possesses four internal rotation axes that can give rise to conformational isomerism (see Scheme 1). The previously reported studies on this molecule are very scarce. Sanz et al. ${ }^{14}$ reported a microwave spectroscopy study of PG, where two conformers were detected in the gas phase: the most stable form, with a cis- $\mathrm{COOH}$ configuration $(\mathrm{O}=\mathrm{C}-\mathrm{O}-\mathrm{H}$ dihedral equal to $\sim 0^{\circ}$ ) and stabilized by two intramolecular hydrogen bonds, one connecting the $\mathrm{NH}_{2}$ group with the $\mathrm{COOH}$ moiety $\left(\mathrm{N}-\mathrm{H}^{\cdots} \mathrm{O}=\mathrm{C}\right)$ and the other established between $\mathrm{NH}_{2}$ and the phenyl ring $\left(\mathrm{N}-\mathrm{H}^{\cdots} \pi\right)$, and a second form, where the carboxylic group is in the trans configuration $(\mathrm{O}=\mathrm{C}-$ $\mathrm{O}-\mathrm{H}$ dihedral equal to $\sim 180^{\circ}$ ) and is bound to the nitrogen atom by an $\mathrm{O}-\mathrm{H} \cdots \mathrm{N}$ type hydrogen bond. In a photoionization and double resonance spectroscopy experiment, Kim et $a l .{ }^{15}$ found a third conformer of the compound, bearing a bifurcated hydrogen bond between the $\mathrm{NH}_{2}$ and $\mathrm{COOH}$ groups. The photochemistry of PG was investigated before by Mittal et al. ${ }^{16}$ and Kim and co-workers, ${ }^{17}$ who observed decarboxylation of the compound upon flash photolysis in aqueous solutions ${ }^{16,17}$ and photoionization of hydrated PG complexes in the gas phase. ${ }^{17}$

Considering the limited information available on the structure and spectroscopy of PG, in the present study we performed a detailed investigation of the potential energy surface of the molecule using density functional theory (DFT) and ab initio (MP2) methods. Then, the molecular form of PG was isolated in argon, nitrogen, and xenon matrices and the conformers of the compound therein present (including a never experimentally observed form) were identified and vibrationally characterized by IR spectroscopy. Subsequently, in situ narrowband near-IR irradiations of the matrix-isolated PG conformers were performed to promote selective conformational conversions, allowing for the generation and characterization of two additional never experimentally observed before conformers of the compound. Finally, the matrix-isolated PG was submitted to UV irradiation $(\lambda=255 \mathrm{~nm})$ and its main photodecomposition reaction channels identified. As shown by kinetic results, distinct preferred photodecomposition channels for cis and trans-COOH type conformers were identified. The interpretation of the spectroscopic and photochemical results received also support from extensive theoretical calculations.

The choice of the matrix isolation method, together with infrared spectroscopy, as the main experimental technique used in the present study resulted from the enormous power of this approach in addressing the type of problems investigated. Indeed, matrix isolation infrared spectroscopy has been very well succeeded in the structural study of conformationally flexible molecules, such as amino acids. Among other amino acids, glycine, ${ }^{6} \alpha$-alanine, ${ }^{7}$ valine, ${ }^{8} \mathrm{~N}, \mathrm{~N}-$ dimethylglycine,${ }^{9}$ serine,${ }^{10}$ phenylalanine,${ }^{11}$ L-alanine, ${ }^{12}$ and $\alpha$-hydoxyisobutyric acid ${ }^{13}$ have been successfully investigated using this approach. The method is quite efficient in trapping different conformers from the gas phase and, because the vibrational spectra obtained in these experimental conditions show higher resolution than those obtained using other sampling techniques, subtle spectroscopic differences due to conformational changes can be clearly identified. In these conditions, the identity of the trapped conformers can be established with certainty. ${ }^{6-13,18-22}$ In addition, the matrix isolation technique generally allows introducing a very convenient simplification when highly flexible molecules are to be analyzed. This simplification results from the reduction of the number of conformers present in the matrices compared to the gas phase, due to conformational cooling effects. ${ }^{23-25}$ When the energy barriers separating higher-energy conformers from lower-energy ones are only of a few $\mathrm{kJ} \mathrm{mol}^{-1}$, conformational cooling can take place during matrix deposition. This leads to conversion of the first forms into the second ones. Besides the simplification introduced regarding the conformational composition, the observation of conformational cooling also provides important clues regarding the conformational dynamics of the studied systems, height of the barriers to internal rotation and relative order of stability of the conformers. ${ }^{23-25}$ Furthermore, it is possible to promote conversions between the matrix-isolated conformers in a precisely controlled way, either by increasing the temperature of the matrix (annealing) or by in situ irradiation with IR or UV/visible light. ${ }^{12,13,18-21}$

\section{EXPERIMENTAL AND COMPUTATIONAL METHODS}

\section{A. Matrix isolation}

For preparing the low temperature matrices, a solid sample of PG obtained from Aldrich (purity 99\%) was sublimated (at $\sim 383 \mathrm{~K}$ ) using a pyrex mini-oven placed in the vacuum chamber of the cryostat (APD Cryogenics close-cycle helium refrigeration system with a DE-202A expander). The vapor of the compound was deposited together with a large excess of inert gas (argon N60, nitrogen N50 or xenon N48, all obtained from Air Liquide), onto a cold (14-20 K) CsI subtrate. Efforts were put in minimizing the presence of aggregates in the as-deposited matrices. Emergence of new bands due to these species upon matrix annealing (when approaching the higher temperatures used in those experiments, which depend on the specific matrix) confirm that in the as-deposited matrices aggregates are present only in trace amounts. The temperature was controlled and measured using a diode sensor connected to a Scientific Instruments digital temperature controller (model 9659) to within $\pm 1 \mathrm{~K}$.

\section{B. Infrared spectroscopy}

The mid-IR spectra $\left(4000-400 \mathrm{~cm}^{-1}\right)$ were collected with $0.5 \mathrm{~cm}^{-1}$ spectral resolution, using a Nicolet 6700 Fourier Transform infrared spectrometer, equipped with a deuterated triglycine sulphate (DTGS) detector and a $\mathrm{Ge} / \mathrm{KBr}$ beamsplitter. The near-IR spectra $\left(7500-2100 \mathrm{~cm}^{-1} ; 1 \mathrm{~cm}^{-1}\right.$ resolution) spectra were recorded using the same spectrometer but equipped with a mercury cadmium telluride (MCT-B) 
detector and $\mathrm{a} \mathrm{CaF}_{2}$ beamsplitter. Modifications of the sample compartment of the spectrometer were made in order to accommodate the cryostat head and allow an efficient purging of the system by a continuous stream of dry air to avoid interference from atmospheric $\mathrm{H}_{2} \mathrm{O}$ and $\mathrm{CO}_{2}$.

\section{Irradiation experiments}

The UV irradiation $(\lambda=255 \mathrm{~nm})$ of the matrices was carried out through the outer quartz window of the cryostat, with the frequency-doubled signal beam of the QuantaRay MOPO-SL pulsed (10 ns) optical parametric oscillator (FWHM $\sim 0.2 \mathrm{~cm}^{-1}$, repetition rate $10 \mathrm{~Hz}$, pulse energy $\sim 1.0 \mathrm{~mJ}$ ) pumped by a Nd:YAG laser. Matrices were also irradiated using the narrowband tunable near-IR light provided by the idler beam of the same equipment.

\section{Computational methodology}

The quantum chemical calculations were performed with the Gaussian 09 suite of programs ${ }^{26}$ at the DFT(B3LYP) $)^{27-29}$ and MP2 ${ }^{30}$ levels of approximation, using the $6-311++G(d, p)$ basis set. ${ }^{31}$ Structures were optimized using the geometry direct inversion of the iterative subspace (GDIIS) method, ${ }^{32}$ with the nature of the obtained stationary points being checked by inspection of the corresponding Hessian matrix. Potential energy profiles for internal rotation were calculated by performing a relaxed scan on the B3LYP/6-311++G(d,p) potential energy surface along the relevant coordinates. The transition state structures for conformational conversions were obtained using the synchronous transit-guided quasi-Newton (STQN) method. ${ }^{33}$
The B3LYP/6-311++G(d,p) calculated vibrational frequencies were scaled by 0.978 (0.944 for $v \mathrm{O}-\mathrm{H}$ stretching mode $)^{34,35}$ and the resulting frequencies, together with the calculated intensities, were used to simulate the spectra shown in the figures. In these simulations, the absorptions were broadened by Lorentzian profiles ( $\mathrm{fwhm}=5 \mathrm{~cm}^{-1}$ ) centered at the calculated (scaled) frequencies, using the SYNSPEC software. ${ }^{36}$ Note that the peak intensities in the simulated spectra (shown in units of "relative intensity") differ from the calculated intensities (in $\mathrm{km} \mathrm{mol}^{-1}$ ), because they were set to satisfy the condition that the integrated band area in the simulated spectrum corresponds to the calculated infrared intensity. The theoretical normal modes were analyzed by carrying out the potential energy distribution (PED) calculations, performed according to the procedure described in Refs. 37 and 38. The set of internal coordinates used in the PED analysis was defined following the recommendations of Pulay et al. ${ }^{39}$ These coordinates are listed in Table S-I in the supplementary material. ${ }^{61}$ The results of the performed normal mode analyses are given in Tables S-II-S-VI in the supplementary material. $^{61}$

\section{RESULTS AND DISCUSSION}

\section{A. Geometries and energies}

Phenylglycine has four different torsional degrees of freedom that can give rise to different conformers (see Scheme 1). After a systematic conformational search on the B3LYP/6-311++G(d,p) potential energy surface of the molecule, 17 different minima were located (Figure 1; see also Table S-VII in the supplementary material for additional views of the obtained minimum energy structures ${ }^{61}$ ). All 17

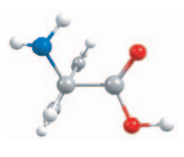

ICa

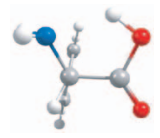

IITa

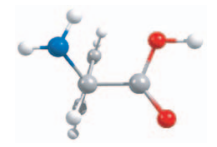

IIICa

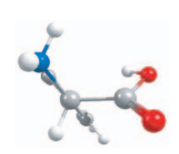

IVTa

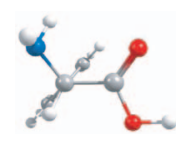

ICb
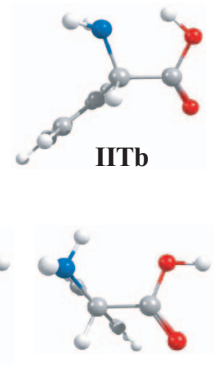

IIICb

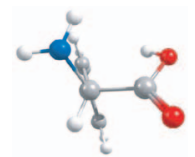

IVTb
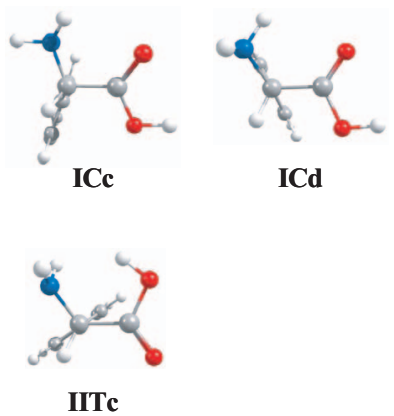

IITc

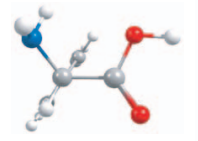

IIICc
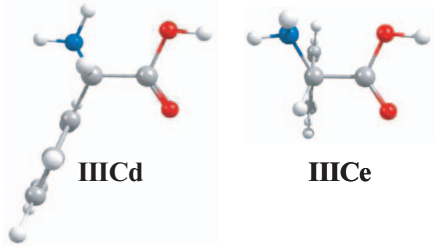

IIICe

FIG. 1. Structures of PG conformers. The conformers have been labeled according to the existence of $\mathrm{N}-\mathrm{H} \cdot \ldots \mathrm{O}=\mathrm{C}($ type $\mathrm{I}$ ), $\mathrm{O}-\mathrm{H} \cdot \ldots \mathrm{N}$ (type II), $\mathrm{N}-\mathrm{H} \cdots \mathrm{O}-\mathrm{H}$ (type III), and $\mathrm{C}=\mathrm{O} \cdots \mathrm{H}-\mathrm{C}$ (type IV) hydrogen bonds in combination with cis- $\mathrm{COOH}\left(\mathrm{C} ; \cong 0^{\circ}\right)$ and trans-COOH $\left(\mathrm{T} \cong 180^{\circ}\right)$ configurations. Color codes: grey $-\mathrm{C}$, red $-\mathrm{O}$, blue $-\mathrm{N}$, white $-\mathrm{H}$. Forms IITb and IITc were not predicted to be minima on the MP2 and DFT(B3LYP) potential energy surfaces, respectively (see text for details). 
TABLE I. Dipole moments $(\mu, \mathrm{D})$ and most relevant dihedral angles $\left(^{\circ}\right)$ of the PG conformers. ${ }^{\mathrm{a}}$

\begin{tabular}{|c|c|c|c|c|c|c|c|c|c|c|}
\hline \multirow[b]{2}{*}{ Form $^{b}$} & \multicolumn{5}{|c|}{$\mathrm{MP} 2 / 6-311++\mathrm{G}(\mathrm{d}, \mathrm{p})$} & \multicolumn{5}{|c|}{ DFT(B3LYP)/6311++G(d,p) } \\
\hline & $\mu$ & $\mathrm{H}-\mathrm{O}-\mathrm{C}=\mathrm{O}$ & $\mathrm{O}-\mathrm{C}-\mathrm{C}-\mathrm{C}$ & $\mathrm{Lp}-\mathrm{N}-\mathrm{C}-\mathrm{C}$ & $\mathrm{C}-\mathrm{C}-\mathrm{C}-\mathrm{ring}$ & $\mu$ & $\mathrm{H}-\mathrm{O}-\mathrm{C}=\mathrm{O}$ & $\mathrm{O}-\mathrm{C}-\mathrm{C}-\mathrm{C}$ & $\mathrm{Lp}-\mathrm{N}-\mathrm{C}-\mathrm{C}$ & $\mathrm{C}-\mathrm{C}-\mathrm{C}-\mathrm{ring}$ \\
\hline $\mathrm{ICd}$ & 1.5 & -2.9 & -83.2 & 43.8 & -16.9 & 1.5 & -2.8 & -83.9 & 40.4 & -25.3 \\
\hline IIICa & 3.0 & -0.7 & 84.7 & 172.7 & 14.6 & 2.7 & -0.4 & 86.0 & 172.3 & 16.0 \\
\hline $\mathrm{IIICb}$ & 1.7 & 2.0 & 83.1 & 51.1 & -39.4 & 1.6 & 1.6 & 83.9 & 47.4 & -42.6 \\
\hline IIICc & 1.9 & 0.9 & 89.2 & 62.3 & 29.0 & 1.7 & 1.6 & 87.9 & 60.5 & 31.0 \\
\hline IIICd & 2.5 & 1.6 & 173.5 & -61.9 & 14.2 & 2.2 & 1.5 & 168.3 & -59.0 & 9.5 \\
\hline IIICe & 1.7 & 1.3 & 91.0 & -56.7 & 9.0 & 1.5 & 1.4 & 97.4 & -54.3 & 2.9 \\
\hline ITa & 5.2 & -173.4 & -33.8 & -42.8 & 10.8 & 4.6 & -174.0 & -31.6 & -40.7 & 7.1 \\
\hline $\mathrm{ITb}$ & 4.3 & -171.7 & -51.5 & 67.7 & 40.7 & 4.1 & -173.6 & -46.5 & 72.0 & 38.7 \\
\hline ITc & 5.4 & -172.7 & -65.8 & 148.2 & 32.8 & 4.7 & -175.1 & -65.8 & 142.4 & 29.0 \\
\hline IVTa & 4.3 & 170.8 & 37.7 & 52.2 & -36.8 & 3.9 & 172.9 & 33.2 & 48.9 & -36.9 \\
\hline IITc & 4.6 & -176.8 & 101.5 & 71.2 & 52.7 & - & 179.9 & 106.2 & 62.9 & 7.3 \\
\hline IVTb & 6.5 & 165.6 & 50.2 & 175.9 & -12.8 & 5.8 & 168.4 & 47.8 & 178.1 & -13.8 \\
\hline
\end{tabular}

${ }^{a}$ The graphical representation of the PG structures is given in Figure 1 (see also Table S-VII in the supplementary material ${ }^{61}$ ). Lp states for the lone pair of the nitrogen atom and $(\mathrm{Lp}-\mathrm{N}-\mathrm{C}-\mathrm{C})$ is defined as $\left[\left(\mathrm{H}_{15}-\mathrm{N}-\mathrm{C}-\mathrm{C}\right)+\left(\mathrm{H}_{16}-\mathrm{N}-\mathrm{C}-\mathrm{C}\right)\right] / 2+180$. Dihedral angle $(\mathrm{C}-\mathrm{C}-\mathrm{C}-$ ring $)$ is defined as $\left[\left(\mathrm{C}_{17}-\mathrm{C}_{12}-\mathrm{C}_{1}-\mathrm{C}_{2}\right)+\left(\mathrm{C}_{17}-\mathrm{C}_{12}-\mathrm{C}_{1}-\mathrm{C}_{6}\right)\right] / 2$, and designates the angle formed by the $\mathrm{C}_{17}-\mathrm{C}_{12}$ bond with the plane perpendicular to the plane of the phenyl ring.

${ }^{b}$ IITb was not found to be a minimum on the PES calculated at the MP2/6-311++G(d,p) level; IITc was not found to be a minimum on the PES calculated at the B3LYP/6$311++\mathrm{G}(\mathrm{d}, \mathrm{p})$ level.

obtained structures resulting from the B3LYP calculations were subsequently reoptimized at the MP2/6-311++G(d,p) level. All resulting conformers belong to the $C_{1}$ symmetry point group.

Since PG has a chiral carbon which leads to the existence of enantiomers with identical vibrational spectra, only the S-enantiomer was considered in the theoretical calcula- tions. The equilibrium Cartesian coordinates (and vibrational frequencies) of all conformers calculated at the two levels of theory used in this study are provided as Supporting Information (Sec. III, Computational Data). ${ }^{61}$

Table I presents the conformationally most relevant dihedral angles of the 17 conformational minima, together with their dipole moments. Table II shows the calculated relative

TABLE II. Relative electronic energies ( $\triangle E$, including the zero-point vibrational energy) and relative Gibbs energies $(\Delta G)$ calculated at the MP2/6-311+G(d,p) and B3LYP/6-311+G(d,p) levels of theory and gas phase equilibrium populations at $383 \mathrm{~K}$ of phenylglycine conformers estimated from the relative Gibbs energies. ${ }^{\text {a }}$

\begin{tabular}{|c|c|c|c|c|c|c|}
\hline \multirow[b]{2}{*}{ Form } & \multicolumn{3}{|c|}{$\mathrm{MP} 2 / 6-311++\mathrm{G}(\mathrm{d}, \mathrm{p})$} & \multicolumn{3}{|c|}{ DFT(B3LYP)/6311++G(d,p) } \\
\hline & $\Delta E$ & $\Delta G$ & $\mathrm{P}_{383 \mathrm{~K}}$ & $\Delta E$ & $\Delta G$ & $\mathrm{P}_{383 \mathrm{~K}}$ \\
\hline $\mathrm{ICa}$ & 0.00 & 0.00 & 30.5 & 0.00 & 1.93 & 18.3 \\
\hline $\mathrm{ICb}$ & 1.59 & 1.63 & 18.3 & 1.19 & 0.00 & 33.6 \\
\hline IITa & 1.96 & 6.22 & 4.3 & 1.15 & 5.69 & 5.6 \\
\hline ICc & 3.04 & 0.55 & 25.7 & 1.85 & 2.78 & 14.0 \\
\hline $\mathrm{IITb}$ & $\ldots{ }^{\mathrm{b}}$ & $\ldots$ & $\ldots$ & 1.87 & 3.65 & $\ldots$ \\
\hline $\mathrm{ICd}$ & 4.54 & 5.45 & 5.5 & 2.78 & 4.68 & 7.7 \\
\hline IIICa & 5.68 & 5.86 & 4.8 & 5.79 & 6.81 & 4.0 \\
\hline $\mathrm{IIICb}$ & 7.08 & 7.56 & 2.8 & 5.31 & 7.30 & 3.4 \\
\hline IIICc & 8.43 & 8.99 & 1.8 & 7.73 & 7.44 & 3.2 \\
\hline IIICd & 8.87 & 7.53 & 2.9 & 8.06 & 5.39 & 6.2 \\
\hline IIICe & 8.88 & 7.77 & 2.7 & 8.61 & 7.42 & 3.3 \\
\hline $\mathrm{ITa}$ & 13.63 & 16.09 & 0.2 & 11.97 & 16.66 & 0.2 \\
\hline $\mathrm{ITb}$ & 16.07 & 15.42 & 0.2 & 15.79 & 15.52 & 0.3 \\
\hline ITc & 18.21 & 15.33 & 0.2 & 17.35 & 14.91 & 0.3 \\
\hline IVTa & 24.14 & 23.19 & 0.0 & 22.20 & 24.71 & 0.0 \\
\hline IITc & 29.94 & 29.41 & $\ldots$ & $\ldots{ }^{b}$ & $\ldots$ & $\ldots$ \\
\hline IVTb & 33.25 & 33.98 & 0.0 & 32.31 & 32.88 & 0.0 \\
\hline
\end{tabular}

${ }^{\text {a }}$ Relative energies are given in $\mathrm{kJ} \mathrm{mol}^{-1}$, populations in $\%$. The calculated electronic energy of the most stable conformer ICa in atomic units is -514.2022479 and -515.6339869 , at MP2/6-311++G(d,p) and B3LYP/311++G(d,p) levels of theory, respectively. The populations of all conformers in the gas phase at $383 \mathrm{~K}$ (the temperature of sublimation of the compound in the matrix isolation experiments) were calculated using the relative Gibbs energy values and assuming the Boltzmann equilibrium. The graphical representation of the PG structures is given in Figure 1 and Table S-VII in the supplementary material. ${ }^{61}$

${ }^{\mathrm{b}} \mathrm{ITb}$ was not found to be a minimum on the PES calculated at the MP2 level and is probably an artifact of the B3LYP calculations (see text). IITc was not found to be a minimum on the PES calculated at the B3LYP level; these two forms were not considered when calculating the abundances of the conformers. 
energies (with zero-point vibrational corrections included) and Gibbs energies of these forms. Both DFT and MP2 results are provided. When comparing experimental with theoretical data for $\Delta E$ and $\Delta G, \mathrm{MP} 2$ calculations generally provide better results than DFT. However, in the case of frequencies, spectra calculated at the DFT level fit the experimental ones much better than those calculated at the MP2 level. The predicted conformers have been labeled according to the nomenclature previously used for $\mathrm{PG},{ }^{14}$ which refers to the existence

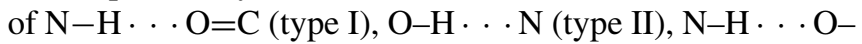
$\mathrm{H}$ (type III), and $\mathrm{C}=\mathrm{O} \cdots \mathrm{H}-\mathrm{C}$ (type IV) hydrogen bonds, in combination with cis- $\mathrm{COOH}\left(\mathrm{C} ; \cong 0^{\circ}\right)$ and trans-COOH $(\mathrm{T}$, $\cong 180^{\circ}$ ) configurations.

Conformational isomers of PG can be grouped on the basis of the type of dominant intramolecular interactions they exhibit. The first group (I) is composed by conformers stabilized by intramolecular hydrogen bonds of $\mathrm{N}-\mathrm{H} \cdot \cdots \mathrm{O}=\mathrm{C}$ type. Within this group, the $\mathrm{COOH}$ group can adopt either a cis (ICa, ICb, ICc, and ICd) or a trans (for ITa, ITb, and ITc) conformation (see Figure 1).

In agreement with previous results, ${ }^{14}$ conformer ICa, bearing a cis-COOH orientation, is the conformational ground state and is stabilized by two hydrogen bonds (N$\mathrm{H} \cdot \cdots \mathrm{O}=\mathrm{C}$ and $\mathrm{N}-\mathrm{H} \cdots \pi)$. This contrasts with what was found for amino acids bearing an aliphatic side-chain, such as alanine ${ }^{7,12}$ and valine, ${ }^{8}$ and also for glycine, ${ }^{6}$ where in the most stable type-I conformer both amino hydrogen atoms interact with the carbonyl oxygen atom, forming a bifurcated bond. In PG, the equivalent conformer of the most stable typeI form of the aliphatic amino acids (and glycine) is form $\mathrm{ICb}$, which corresponds to the second most stable form of PG.

The relative energy of conformer $\mathrm{ICb}\left(1.19 \mathrm{~kJ} \mathrm{~mol}^{-1}\right.$ at the B3LYP level; $1.59 \mathrm{~kJ} \mathrm{~mol}^{-1}$ at the MP2 level; see Table II) indicates that in PG the stabilization energy of a single $\mathrm{N}-\mathrm{H} \cdots \mathrm{O}=\mathrm{C}$ bond plus an $\mathrm{N}-\mathrm{H} \cdots \pi$ interaction (as in ICa) is larger than that of a bifurcated $\mathrm{N}-\mathrm{H} \cdot \cdots \mathrm{O}=\mathrm{C}$ hydrogen bond (as in $\mathrm{ICb}$ ).

Conformer ICc possesses a single $\mathrm{N}-\mathrm{H} \cdots \mathrm{O}=\mathrm{C}$ bond, with the second amino hydrogen atom not involved in any hydrogen bond. Although this conformer is also stabilized by an interaction between the lone pair of the nitrogen atom and one of the hydrogen atoms of the phenyl ring $\left(\mathrm{N}_{\mathrm{Lp}} \cdot \mathrm{H}-\mathrm{C}_{\text {ring }}\right)$, this conformer is predicted to have a higher energy compared to the other two previously discussed type-I cis-COOH forms (ICa and ICb) $\left(\Delta E_{\mathrm{ICc}-\mathrm{ICa}}=1.85 \mathrm{~kJ} \mathrm{~mol}^{-1}\right.$ as predicted by the DFT calculations; MP2: $3.04 \mathrm{~kJ} \mathrm{~mol}^{-1}$ ).

The highest energy type-I cis-COOH conformer of PG is conformer ICd $\left(\Delta E_{\mathrm{ICd}-\mathrm{ICa}}=2.78 \mathrm{~kJ} \mathrm{~mol}^{-1}\right.$, according to the DFT method; MP2: $4.54 \mathrm{~kJ} \mathrm{~mol}^{-1}$ ). Like ICb, this conformer has both amino hydrogen atoms interacting with the carbonyl oxygen atom in a bifurcated $\mathrm{N}-\mathrm{H} \cdots \mathrm{O}=\mathrm{C}$ bond, but the conformations about the two exocyclic $\mathrm{C}-\mathrm{C}$ bonds and the $\mathrm{C}-\mathrm{N}$ bond are slightly different in the two conformers (see Table I). Such geometric arrangements make the N-H . . O distances larger in $\mathrm{ICd}$ than in $\mathrm{ICb}$ [in particular, the $\mathrm{N}-\mathrm{H}_{16} \cdots \mathrm{O}$ distance in ICd (314.0 pm) is rather long compared to ICb (288.0 $\mathrm{pm})$ ], leading to a weaker $\mathrm{H}$-bond in $\mathrm{ICd}$ compared to $\mathrm{ICb}$, and thus justifying their relative energies.
In conformers ITa, ITb, and ITc, the carboxylic group is in the energetically less favorable trans geometry, which explains their high relative energies (over $\sim 12 \mathrm{~kJ} \mathrm{~mol}^{-1}$, in relation to ICa; see Table II).

Conformers of type II exhibit an intramolecular $\mathrm{O}-\mathrm{H} \cdot \mathrm{N}$ hydrogen bond. Like in other amino acids, ${ }^{6-14}$ this $\mathrm{O}-\mathrm{H} \cdot \cdots \mathrm{N}$ hydrogen bond has a strong stabilizing effect that partially compensates the less favorable trans configuration of the carboxylic group. Three PG structures belonging to this group resulted from the calculations: IITa, IITb, and IITc. However, among them only IITa appears to be a relevant conformer of PG. This form exhibits the largest charge separation within the molecule, which is well reflected in its largest dipole moment (4.59 D) and justifies its previous observation by microwave spectroscopy. ${ }^{14}$ Interestingly, among the trans carboxylic conformers, there is a trend that the more stable the conformer, the larger its dipole moment. This issue has been discussed for other compounds, including dimethylglycine, sarcosine, and ethylthiocrotonate, among others. ${ }^{9,40,41}$

$\mathrm{IITb}$ is not a minimum on the MP2/6-311++G(d,p) potential energy surface of the molecule, where all attempts to optimize this form (using different optimization convergence criteria) converged to the IITa conformer. Therefore, considering the usual better performance of the MP2 method (compared to the DFT/B3LYP one) in predicting details of the potential energy surfaces, particularly in molecules where dispersion forces might play an important role, it seems probable that IITb is not a real minimum, but an artifact of the calculations at the B3LYP level. In turn, IITc is not a minimum at the DFT level and corresponds to a very high energy local minimum at the MP2 level $\left(\Delta E_{\mathrm{IITc}-\mathrm{ICa}} \sim 30 \mathrm{~kJ} \mathrm{~mol}^{-1}\right)$.

Type-III conformers (IIICa, IIICb, IIICc, IIICd, and IIICe) are stabilized by an $\mathrm{N}-\mathrm{H} \cdots \mathrm{O}-\mathrm{H}$ hydrogen bond, all of them adopting a cis- $\mathrm{COOH}$ configuration. The relative energies $(\Delta E)$ of these conformers at the MP2 level of theory are $5.68,7.08,8.43,8.87$, and $8.88 \mathrm{~kJ} \mathrm{~mol}^{-1}$, respectively.

Type-IV conformers (IVTa and IVTb) exhibit an intramolecular $\mathrm{C}=\mathrm{O} \cdots \mathrm{H}-\mathrm{C}$ hydrogen bond and a trans$\mathrm{COOH}$ configuration. Due to the weaker character of the $\mathrm{C}=\mathrm{O} \cdots \mathrm{H}-\mathrm{C}$ bonds, all these conformers have relative energies higher than $20 \mathrm{~kJ} \mathrm{~mol}^{-1}$.

In summary, among the calculated minimum energy structures of PG type-III and type-IV conformers correspond to high or very-high energy forms that can be expected to be weakly populated in the gas phase (Note: we considered here $383 \mathrm{~K}$ as the reference temperature because it is the temperature used to deposit the compound in experimental conditions of this study), whereas among the type-II rotameric structures, the IITa form appears as the only conformer having experimental relevance. In relation to type-I forms, one can conclude that, while the trans-COOH forms correspond to high-energy conformers of no practical relevance in the gas phase equilibrium, the cis- $\mathrm{COOH}$ forms are all low-energy conformers (below $\sim 5 \mathrm{~kJ} \mathrm{~mol}^{-1}$ ) which have to be taken into account as relevant contributors to the conformational equilibrium in the gas phase. Conformers ICa and IITa correspond to the two forms previously observed by microwave spectroscopy, ${ }^{14}$ while ICb corresponds to the form claimed to 
TABLE III. Theoretical values of conformational interconversion barriers for cis-COOH conformers of PG. ${ }^{\mathrm{a}}$

\begin{tabular}{|c|c|c|c|c|c|c|c|c|c|}
\hline \multirow[b]{2}{*}{ Reactant } & \multicolumn{9}{|c|}{ Product } \\
\hline & $\mathrm{ICa}$ & $\mathrm{ICb}$ & ICc & $\mathrm{ICd}$ & IIICa & $\mathrm{IIICb}$ & IIICc & IIICd & IIICe \\
\hline $\mathrm{ICa}$ & $\ldots$ & 5.9 (TS1) & 16.7 (TS2) & & $\begin{array}{l}21.7 \text { (TS3) } \\
27.4 \text { (TS4) }\end{array}$ & & & & \\
\hline $\mathrm{ICb}$ & 3.9 (TS1) & $\ldots$ & 8.1 (TS5) & $\begin{array}{l}1.9 \text { (TS6) } \\
3.4 \text { (TS7) }\end{array}$ & & & $\begin{array}{l}13.4 \text { (TS8) } \\
16.1 \text { (TS9) }\end{array}$ & & \\
\hline $\mathrm{ICc}$ & 13.9 (TS2) & 7.2 (TS5) & $\ldots$ & & & & & $10.8(\mathrm{TS} 11)$ & $9.3(\mathrm{TS} 12)$ \\
\hline ICd & & $\begin{array}{l}1.1 \text { (TS6) } \\
2.6 \text { (TS7) }\end{array}$ & & $\ldots$ & & $\begin{array}{l}13.7 \text { (TS13) } \\
14.9 \text { (TS14) }\end{array}$ & & & \\
\hline IIICa & $\begin{array}{l}15.8 \text { (TS3) } \\
21.6 \text { (TS4) }\end{array}$ & & & & $\ldots$ & & $8.6(\mathrm{TS} 15)$ & & $11.8(\mathrm{TS} 16)$ \\
\hline $\mathrm{IIICb}$ & & & & $\begin{array}{l}11.3 \text { (TS13) } \\
12.5 \text { (TS14) }\end{array}$ & & $\ldots$ & $\begin{array}{l}3.5 \text { (TS17) } \\
4.6 \text { (TS18) }\end{array}$ & & \\
\hline IIICc & & $\begin{array}{c}7.3 \text { (TS8) } \\
10.0 \text { (TS9) }\end{array}$ & & & $6.5(\mathrm{TS} 15)$ & $\begin{array}{l}0.6 \text { (TS17) } \\
1.7 \text { (TS18) }\end{array}$ & $\ldots$ & & 8.4 (TS19) \\
\hline IIICd & & & $4.5(\mathrm{TS} 11)$ & & & & & & 0.7 (TS10) \\
\hline IIICe & & & 2.9 (TS12) & & 8.5 (TS16) & & 7.3 (TS19) & $0.6(\mathrm{TS} 10)$ & $\ldots$ \\
\hline
\end{tabular}

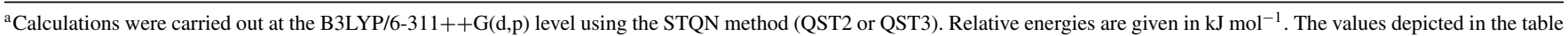
do not include the zero-point correction to energy. The involved transition states are provided in parentheses after the corresponding energy values and keep the naming used in Figure $\mathrm{S} 1$ in the supplementary material. ${ }^{61}$

have been observed in the photoionization and double resonance spectroscopy experiments reported by Kim et al. ${ }^{15}$

\section{B. Estimated abundance of PG conformers (in gas phase and in the cryogenic matrices) and conformational interconversion barriers}

The calculated relative Gibbs energies for PG conformers are provided in Table II, together with the corresponding equilibrium populations in the gas phase at $383 \mathrm{~K}$ (the sublimation temperature used in the experimental conditions of this study) estimated using the relative Gibbs energies and assuming the Boltzmann distribution.

It is clear from Table II that the Gibbs energies at $383 \mathrm{~K}$ do not follow the order of the zero-point-corrected relative energies. Thus, it is evident that entropy effects are important for the thermochemistry of PG in gas phase and must be taken into account when determining the experimental relative abundances of the various conformers, as was also shown to happen, for example, in case of phenylalanine and serine. ${ }^{10,11}$ The most striking effect of entropy is the considerable destabilization of conformer IITa relatively to the remaining forms (see Table II). This relative entropy destabilization of IITa can be ascribed to the effect of the increased conformational rigidity caused by the presence of the strong $\mathrm{O}-\mathrm{H} \cdots \mathrm{N}$ hydrogen bond in this form.

In order to predict which conformers are expected to be trapped from the gas phase into the cryogenic matrices, besides their relative energies, the energy barriers separating higher-energy conformers from lower-energy ones shall also be considered. As mentioned in the Introduction, if these barriers are low enough, the higher-energy forms can promptly relax into lower-energy forms during matrix deposition and are not possible to be trapped in the matrices. ${ }^{22-25}$ Therefore, the conformational interconversion barriers between the PG forms whose gas phase predicted populations at $383 \mathrm{~K}$ are above $1 \%$ were calculated. These forms correspond to all cis-
$\mathrm{COOH}$ conformers and the IITa form (see Table II). However, the barriers of isomerization of IITa into any other species (in particular $\mathrm{ICa}$ and $\mathrm{ICb}$, which have lower energies than IITa) can be anticipated to be rather large, due to the requirement of breaking the strong $\mathrm{O}-\mathrm{H} \cdots \mathrm{N}$ hydrogen-bond, besides the extensive structural rearrangement of the molecular skeleton. The computed interconversion energy barriers are presented in Table III. The most relevant potential energy profiles are provided in Figure S1 in the supplementary material. ${ }^{61}$

The existence of low barriers separating some of the cis$\mathrm{COOH}$ forms led to simplify the conformational picture expected to be trapped in the matrices. For example, the ICd $\rightarrow$ ICb conversion requires just a rotation about the $\mathrm{C}_{12}-\mathrm{C}_{1}$ bond (the value of $\mathrm{C}_{17}-\mathrm{C}_{12}-\mathrm{C}_{1}$-ring dihedral in ICd is $-25.3^{\circ}$ and $40.9^{\circ}$ in $\mathrm{ICb}$, see Table I), thus resulting in a very low barrier of $1.1 \mathrm{~kJ} \mathrm{~mol}^{-1}$ (TS6; $1.9 \mathrm{~kJ} \mathrm{~mol}^{-1}$ in the reverse direction). Also, the conversion $\mathrm{ICb} \rightarrow \mathrm{ICa}$ involves the rotation of the amino group about the $\mathrm{C}-\mathrm{N}$ bond (the $\mathrm{Lp}-\mathrm{N}-\mathrm{C}-\mathrm{C}$ dihedral angle turns from $60.7^{\circ}$ to $159.4^{\circ}$ ), resulting in a low barrier of $3.9 \mathrm{~kJ} \mathrm{~mol}^{-1}$ (TS1, $5.9 \mathrm{~kJ} \mathrm{~mol}^{-1}$ in the reverse direction) too. Therefore, it is expected that conformers ICd and $\mathrm{ICb}$ are likely to relax to conformer ICa (conversion: ICd $\rightarrow$ $\mathrm{ICb} \rightarrow \mathrm{ICa}$ ) upon deposition of the matrix (see also Figure S1 in the supplementary material). ${ }^{61}$

The equivalent of type-III conformers have not been detected upon deposition of other amino acids, such as alanine, ${ }^{7,12}$ phenylalanine, ${ }^{11}$ and $\alpha$-aminoisobutyric acid. ${ }^{13}$ This observation was also explained considering the conformational relaxation of type-III forms into conformers of typeI during matrix deposition. In PG, the direct conversions of IIICa, IIICb, and IIICc into ICa are difficult because of the high energy barriers involved [e.g., the conversion IIICa $\rightarrow$ ICa requires $15.8 \mathrm{~kJ} \mathrm{~mol}^{-1}$ (TS3); see Table III)]. However, stepwise conversions seem to be plausible (see Table III and Figure S1 in the supplementary material): ${ }^{61}$ for example, the conversions IIICa $\rightarrow$ IIICc (TS15) and IIICb $\rightarrow$ IIICc (TS17) 
TABLE IV. Theoretical values of conformational conversion barriers for trans-cis COOH internal rotation in PG. ${ }^{\text {a }}$

\begin{tabular}{|c|c|c|c|c|c|c|c|c|}
\hline \multirow[b]{2}{*}{ Reactant } & \multicolumn{8}{|c|}{ Product } \\
\hline & $\mathrm{ICa}$ & $\mathrm{ICb}$ & $\mathrm{ICc}$ & IIICe & ITa & $\mathrm{ITb}$ & ITc & IITa \\
\hline $\mathrm{ICa}$ & $\ldots$ & & & & & & $\begin{array}{l}50.8(\mathrm{TS} 20) \\
54.0(\mathrm{TS} 21)\end{array}$ & \\
\hline $\mathrm{ICb}$ & & $\ldots$ & & & & $\begin{array}{l}47.0(\mathrm{TS} 22) \\
53.8(\mathrm{TS} 23)\end{array}$ & & \\
\hline $\mathrm{ICc}$ & & & $\ldots$ & & $\begin{array}{l}44.9 \text { (TS26) } \\
54.1 \text { (TS27) }\end{array}$ & & & \\
\hline IIICe & & & & $\ldots$ & & & & $\begin{array}{l}49.0(\mathrm{TS} 24) \\
53.1(\mathrm{TS} 25)\end{array}$ \\
\hline ITa & & & $\begin{array}{l}35.4 \text { (TS26) } \\
44.7 \text { (TS27) }\end{array}$ & & $\ldots$ & & & \\
\hline $\mathrm{ITb}$ & & $\begin{array}{l}31.9(\mathrm{TS} 22) \\
38.6(\mathrm{TS} 23)\end{array}$ & & & & $\ldots$ & & \\
\hline ITc & $\begin{array}{l}31.7(\mathrm{TS} 20) \\
34.9(\mathrm{TS} 21)\end{array}$ & & & & & & $\ldots$ & \\
\hline IITa & & & & $\begin{array}{l}58.4(\mathrm{TS} 24) \\
62.5(\mathrm{TS} 25)\end{array}$ & & & & $\ldots$ \\
\hline
\end{tabular}

a Calculations were carried out at the B3LYP/6-311++G(d,p) level using the STQN method (QST2 or QST3). Relative energies are given in $\mathrm{kJ}$ mol ${ }^{-1}$. The values depicted in the table do not include the zero-point correction to energy. The involved transition states are provided in parentheses after the corresponding energy values, and keep the naming used in Figure $\mathrm{S} 2$ in the supplementary material. ${ }^{61}$

involve relatively low energies, and the conversion of IIICa into ICa via ICb seems also possible to take place during deposition (all relevant barriers were predicted to be less than $\sim 8.5 \mathrm{~kJ} \mathrm{~mol}^{-1}$ ).

Other expected conversions of PG conformers taking place during matrix deposition are the IIICe $\rightarrow$ IIICd $\rightarrow$ ICc (the IIICe $\rightarrow$ IIICd conversion requires only $0.6 \mathrm{~kJ} \mathrm{~mol}^{-1}$ (TS10) and the IIICd $\rightarrow$ ICc one, $4.5 \mathrm{~kJ} \mathrm{~mol}^{-1}$ (TS11).

On the other hand, the ICc $\rightarrow$ ICa conversion is associated with a barrier of $13.9 \mathrm{~kJ} \mathrm{~mol}^{-1}$ (TS2), that might be high enough to preclude this process to occur during matrix deposition. Taking into account these data and the low relative energy of ICc $\left(1.85 \mathrm{~kJ} \mathrm{~mol}^{-1}\right.$ at the B3LYP level; $3.04 \mathrm{~kJ}$ $\mathrm{mol}^{-1}$ at the MP2 level; Table II), it can be concluded that, in principle, this form shall be trapped in the matrices together with ICa and IITa forms and is susceptible of experimental detection.

Table IV shows the calculated energy barriers for internal rotation within the carboxylic group (trans-cis isomerizations). Figure $\mathrm{S} 2$ in the supplementary material shows the corresponding calculated potential energy profiles. ${ }^{61}$ As expected, these barriers are considerably high, all being over 31 $\mathrm{kJ} \mathrm{mol}^{-1}$ in the higher-energy form (trans) $\rightarrow$ lower-energy form (cis) direction. As it will be shown later on, interconversions Ica $\leftrightarrow$ ITc (TS20 and TS21; see Figure S2 in the supplementary material) ${ }^{61}$ and ICc $\leftrightarrow$ ITa (TS26 and TS27; see Figure $\mathrm{S} 2$ in the supplementary material ${ }^{61}$ appear particularly relevant in the context of the present study. Following the general rule, the barriers for these processes are higher than $31 \mathrm{~kJ} \mathrm{~mol}^{-1}$, thus making impossible these conversions to take place via an over-the-barrier mechanism in the matrix conditions.

Summarizing, the theoretical results indicate that three conformers are expected to be experimentally observed in the matrix isolation conditions of this work: ICa, whose population shall be the sum of the populations of $\mathrm{ICa}, \mathrm{ICb}, \mathrm{ICd}$,
IIICa, IIICb, and IIICc in the gas phase equilibrium at $383 \mathrm{~K}$; ICc, with a population equal to the sum of ICc, IIICd, and IIICe populations in the gas phase, and IITa (the population of all other trans- $\mathrm{COOH}$ forms in the gas phase at $383 \mathrm{~K}$ are predicted to be nearly zero; see Table II). This means that the expected populations for ICa, ICc, and IITa conformers in the matrices are $\sim 64,31$ and 5\%, respectively (MP2 based values).

\section{Infrared spectra of matrix-isolated PG}

The experimental infrared spectra of monomeric PG isolated in argon, nitrogen, and xenon matrices are presented in Figure 2, together with the B3LYP/6-311++G(d,p) calculated spectra of conformers ICa, ICc, and IITa, weighted by their expected relative populations (64\% ICa, $31 \%$ ICc, and $5 \%$ IITa). The fairly good agreement between the experimental and the theoretical spectra supports the presence of conformers ICa, ICc, and IITa in the matrices, as expected on the basis of the theoretical calculations described in Secs. III A and III B (see Figure 2).

It shall be noticed that the spectra are complex because of the extensive site splitting. This is particularly evident in the case of the most intense bands ascribed to vibrations mostly related with polar molecular fragments (e.g., the $\nu \mathrm{OH}$ and $\nu \mathrm{CO}$ modes) or those that are sensitive to small structural changes caused by the environment. Indeed, the most striking examples of these effects are observed in the two predicted vibrations of the ICa conformer that have a dominant contribution from the $\mathrm{wNH}_{2}$ coordinate (predicted at 875 and 801 $\mathrm{cm}^{-1}$ ). This coordinate is well-known to be extremely sensitive to environment and subtle structural changes of the $\mathrm{NH}_{2}$ fragment. ${ }^{42,43}$ In the experimental spectra, the signals due to these vibrations appear as multiplets smeared within a relatively wide frequency range. 

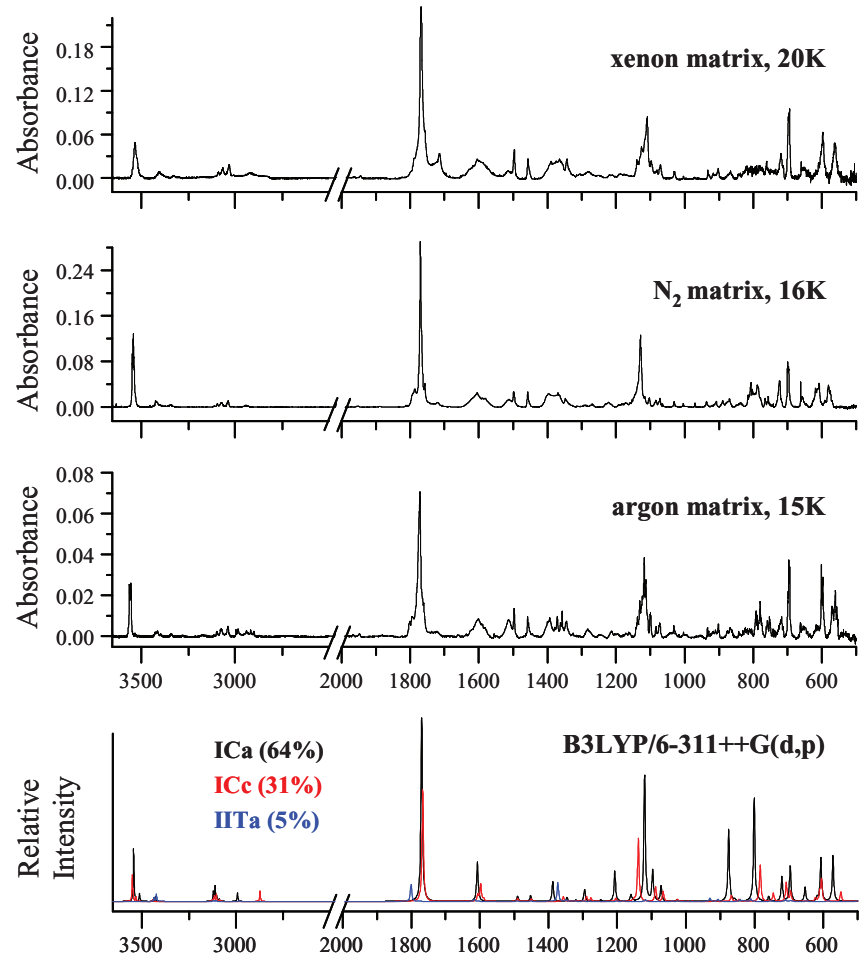

Wavenumber $/ \mathrm{cm}^{-1}$

FIG. 2. Comparison of the FT-IR spectra of monomeric PG isolated in argon matrix at $15 \mathrm{~K}$, nitrogen matrix at $16 \mathrm{~K}$, and xenon matrix at $20 \mathrm{~K}$, with the simulated spectrum at the B3LYP/6 $311++\mathrm{G}(\mathrm{d}, \mathrm{p})$ level, considering the presence of three conformers, ICa (black), ICc (red), and IITa (blue) in the theoretically predicted ratio of $64 \%: 31 \%: 5 \%$, respectively. The calculated frequencies scaled by 0.978 and 0.944 for the $v \mathrm{O}-\mathrm{H}$ stretching region.

For the argon matrix experiments, annealing to higher temperatures showed that there are some sites considerably more stable than others, less stable sites converting into the more stable ones upon annealing at $\sim 27 \mathrm{~K}$. Figure 3(a) shows the changes in the $\mathrm{OH}$ stretching region of the spectrum of $\mathrm{PG}$ in argon matrix as a result of annealing. Bands corresponding to ICa and ICc conformers trapped in at least five and three main matrix sites, respectively, are observed in this spectral range. Upon increasing the temperature of the matrix up to 27 $\mathrm{K}$, the intensity of bands ascribed to the most stable sites of both conformers (marked with a " + " signal in the figure) enhances at expenses of bands corresponding to the less stable sites (“-”). At $36 \mathrm{~K}$, bands of ICc (all sites) strongly decreased in favor of ICa bands, showing that at this temperature conformer ICc converts into the most stable ICa form. This is an additional fact pointing to the presence of both ICa and ICc conformers in the matrices, and also a proof that $\mathrm{ICa}$ has a lower energy than ICc.

Note also that the site splitting effect is less pronounced in the nitrogen matrix than in argon, as expected taking into account the stronger specific interactions of PG molecules with the host molecules (in particular through formation of $\mathrm{O}-\mathrm{H} \cdot \mathrm{N}_{2}$ complexes). ${ }^{44}$ Such strong specific interactions lead to a selection of sites with increased stability, a priori eliminating the low-stability sites. According to this interpretation, all sites in the nitrogen matrix appear to have a similar stability, as no changes in the relative intensity of the cor- responding component-bands were observed upon annealing until ICc started to convert into ICa at around $36 \mathrm{~K}$. In xenon matrices, site splitting was also found to be considerably less important than in argon, due to the usual band broadening and overlapping.

It shall also be stressed that the performed annealing experiments did not lead to a doubtless assignment of the full sets of bands corresponding to individual conformers, but only in a few cases. This was due to the extensive overlap of the majority of the bands originated in the different conformers, complicated additionally by the aforementioned site splitting (in $\mathrm{Ar}$ and $\mathrm{N}_{2}$ matrices) or broadness of the bands (in $\mathrm{Xe}$ ). The $v \mathrm{OH}$ spectral region is in fact the region where bands corresponding to each of the three conformers, ICa, ICc, and IITa, could be more easily identified. Both ICa and $\mathrm{ICc}$, where the $\mathrm{OH}$ group is not participating in any hydrogen bond as donor, give rise to signals at the typical frequency of a "free" $\nu \mathrm{OH}$ mode of a monomeric cis- $\mathrm{COOH}$ group, i.e., at $\sim 3560 \mathrm{~cm}^{-1}$ (multiplet with higher wavenumber components being due to $\mathrm{ICc}$, and lower wavenumber components being ascribable to ICa; see Figure 3). On the other hand, the $v \mathrm{O}-\mathrm{H}$ vibration of the strongly $\mathrm{O}-\mathrm{H} \cdots \mathrm{N}$ hydrogen bonded conformer IITa gives rise to a very broad band with maximum absorbance at $\sim 3414 \mathrm{~cm}^{-1}$, in a similar way to what was observed, for example, for the analogue conformer of $\beta$ aminoisobutyric acid. ${ }^{13}$

Other modes mainly localized in the carboxylic moiety give rise to non-overlapped bands, thus allowing the assignment of the corresponding bands to the conformers. For instance, in IITa the $\delta \mathrm{OH}$ and $\nu \mathrm{CO}$ modes are predicted to occur at 1372.9 and $1200.8 \mathrm{~cm}^{-1}$, with intensities of 365.9 and 7.9 $\mathrm{km} \mathrm{mol}^{-1}$, respectively. The same vibrations are predicted at much lower frequencies in both ICa $\left(1294.6\right.$ and $1120.0 \mathrm{~cm}^{-1}$, with intensities of 18.1 and $190.7 \mathrm{~km} \mathrm{~mol}^{-1}$, respectively) and in ICc (1289.8 and $1139.0 \mathrm{~cm}^{-1}$, with intensities of 15.9 and $196.9 \mathrm{~km} \mathrm{~mol}^{-1}$, respectively). The intense $\delta \mathrm{OH}$ band of the IITa form and the intense $v \mathrm{CO}$ bands of the ICa and ICc forms appear in spectral regions where no other intense bands are predicted. Hence, they could be ascribed as major contributors to the features observed in the $1400-1455 \mathrm{~cm}^{-1}$ and $1138-1113 \mathrm{~cm}^{-1}$ ranges, respectively. Also, the bands in the $935-900 \mathrm{~cm}^{-1}$ range could be ascribed to the theoretically predicted bending modes at 929.9 and $906.3 \mathrm{~cm}^{-1}$ of the IITa conformer, which have dominant contributions of the $\mathrm{wNH}_{2}$ coordinate.

The full, doubtless assignment of the bands observed in the infrared spectra to the individual ICa, ICc, and IITa conformers could however be undertaken with help of the NIRirradiation experiments described in Sec. III D. The proposed band assignments, together with the PED analyses for these three conformers, are provided in Tables S-II-S-IV in the supplementary material. $^{61}$

\section{Narrowband near-IR generation of high-energy conformers of PG and detailed assignment of the IR experimental spectra to individual conformers}

The use of present-day tunable laser sources allows a detailed investigation of NIR-induced selective conformational 


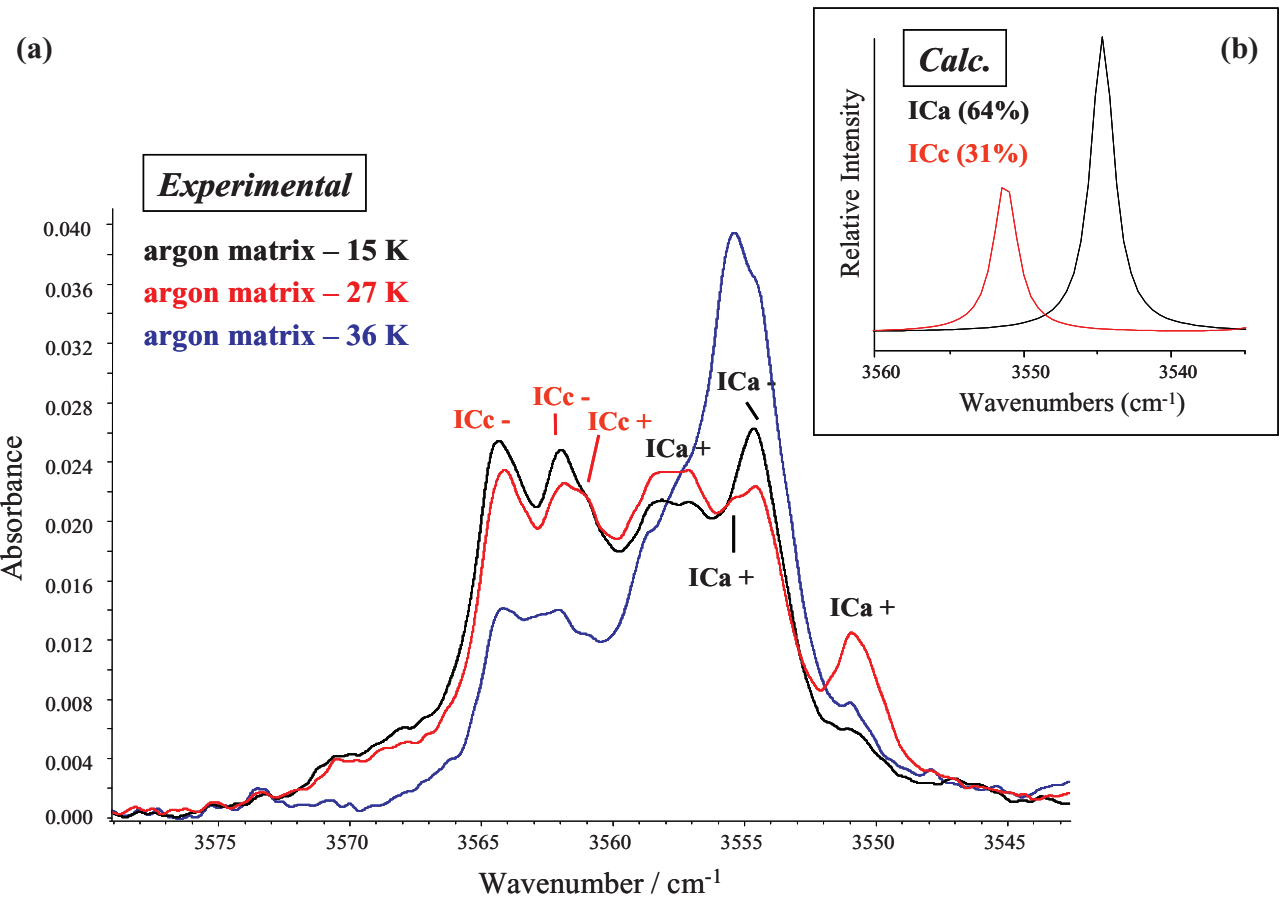

FIG. 3. (a) Experimental IR spectrum (3580-3540 $\mathrm{cm}^{-1}$ region; $\left.v \mathrm{OH}\right)$ of $\mathrm{PG}$ trapped in argon at $15 \mathrm{~K}$ and spectra obtained after annealing at $27 \mathrm{~K}$ and $36 \mathrm{~K}$. The "+" and "-" symbols indicate bands assigned to ICc and ICa conformers more and less stable matrix sites, respectively. (b) B3LYP/6-311++G(d,p) calculated $\nu \mathrm{OH}$ IR bands for ICc and ICa conformers. Theoretical intensities were scaled by the computed abundance, $64 \%$ and $31 \%$, respectively, and wavenumbers were scaled by 0.944 .

isomerization processes for matrix-isolated molecules. Narrowband excitation at the spectral position of a specific NIR absorption of a given conformer may lead to its selective conversion into another form, eventually to the generation of new conformers whose abundance in the gas phase is very low to be experimentally detected. In our experimental set up, the condition for this to be possible is that the new conformers generated upon NIR excitation are stable enough in the cryogenic matrices to be detected by infrared stationary spectroscopy. In the case of molecules bearing a carboxylic acid moiety, it has been shown that selective irradiation at the frequency of the first $\mathrm{OH}$ stretching overtone of the cis- $\mathrm{COOH}$ conformers leads to production of the generally higher energy forms bearing the $\mathrm{COOH}$ group in the trans arrangement. However, in most of the cases the newly generated higherenergy conformer converts back to the initial cis form, by tunneling, on a time scale of fractions of a second to a few minutes, in cryogenic noble gas matrices. ${ }^{45-47}$ Nevertheless, the lifetime of such NIR-generated species can be extended by using solid nitrogen as matrix host, instead of a solid noble gas. This effect has been demonstrated for several matrixisolated molecules. $^{12,13,41,48-50}$

For PG in a nitrogen matrix, the first overtone of the $\nu \mathrm{O}-\mathrm{H}$ vibration of $\mathrm{ICa}$ and ICc conformers is observed in the $6940-6885 \mathrm{~cm}^{-1}$ range (see Figure S3 in the supplementary material) ${ }^{61}$ as an overlapped and site-splitted multicomponent band. On the other hand, the $v \mathrm{O}-\mathrm{H}$ overtone of the IITa conformer shall give rise to a very broad feature at much lower frequencies, consistently with the characteristic profile of its fundamental vibration. The broadness of the band, to- gether with the low intensity expected for an overtone, precluded its experimental observation. Once the position of the $v \mathrm{O}-\mathrm{H}$ overtone band of the ICa and ICc conformers was experimentally determined, irradiations of the matrix-isolated PG at selected frequencies within the envelope of the band were performed. Since this absorption is much broader than the bandwidth of the used irradiation source, we were able to explore the effect of different irradiations by tuning the nearinfrared beam at slightly different positions within the broad overtone absorption.

In the first experiment, irradiation was performed at 6930 $\mathrm{cm}^{-1}$, which corresponds to the high wavenumber component of the $\nu \mathrm{O}-\mathrm{H}$ overtone broad band multiplet. The changes induced by the NIR irradiation were monitored by collecting spectra in the mid-IR region. As result of the irradiation at $6930 \mathrm{~cm}^{-1}$, a selective consumption of ICc bands was observed, while those ascribable to IITa increased. Simultaneously, a new set of bands due to a new species started increasing. Figure 4(a) shows the experimental difference spectrum obtained by subtracting the spectrum of the as-deposited matrix from the spectrum obtained after NIR irradiation at 6930 $\mathrm{cm}^{-1}$. This difference spectrum is very well reproduced by the theoretical (0.6 ITa + 0.4 IITa) minus ICc difference spectrum shown in the same figure.

In a second experiment, NIR irradiation of the sample was performed at $6910 \mathrm{~cm}^{-1}$, which stays in the low wavenumber range of the $v \mathrm{O}-\mathrm{H}$ overtone band. After this irradiation, a selective consumption of the ICa bands was observed in the mid-IR spectrum, while a different set of new bands emerged. Once again, the bands of IITa form were 
(a)
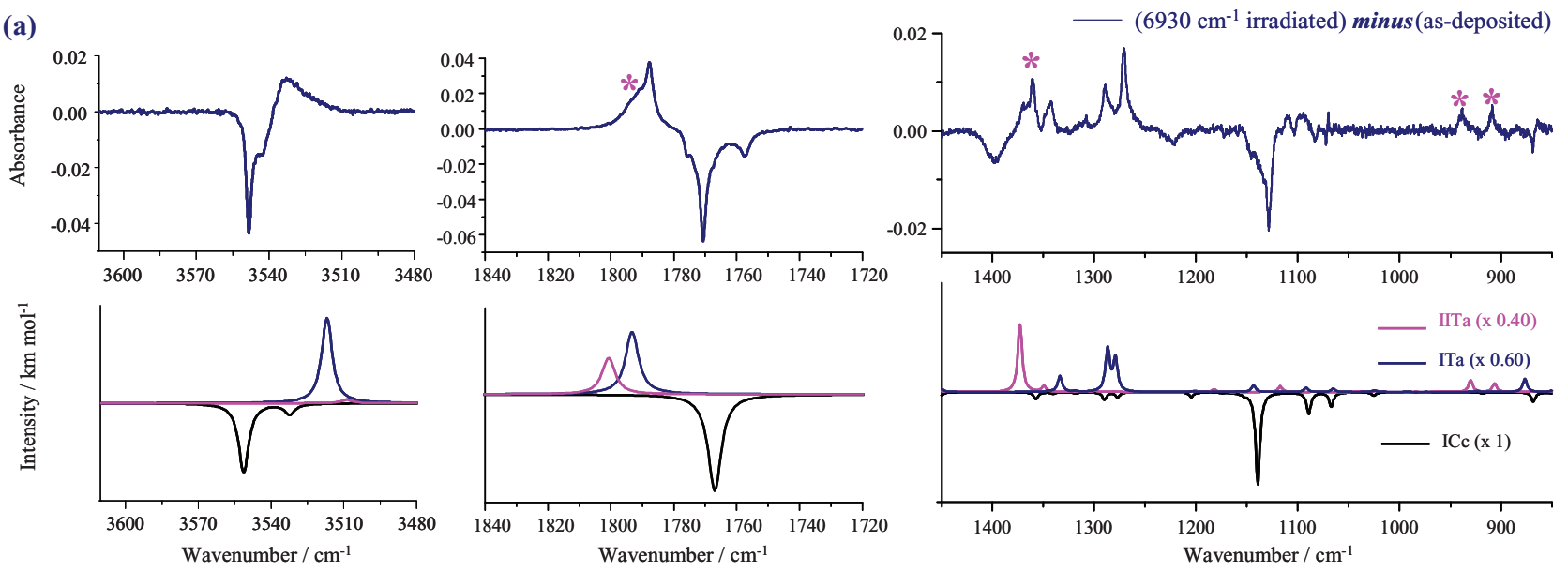

(b)
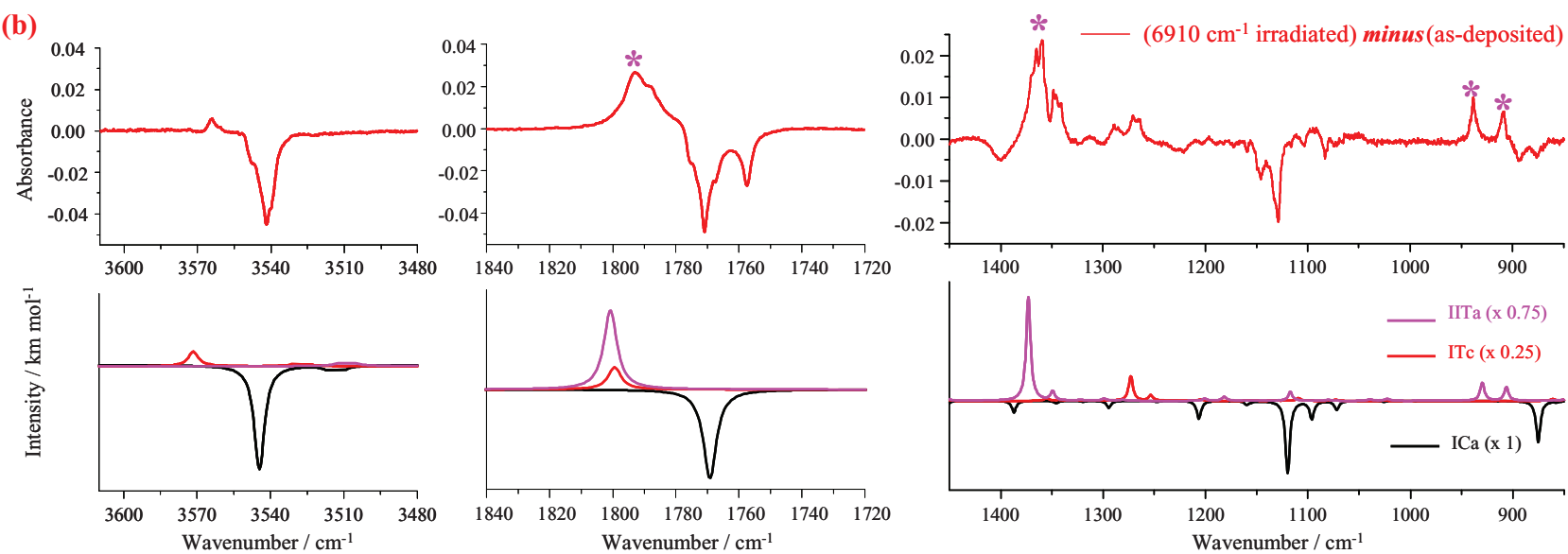

FIG. 4. Experimental IR difference spectra: (a) blue line - spectrum obtained after the irradiation at $\lambda=6930 \mathrm{~cm}^{-1}$ "minus" spectrum of the as-deposited $\mathrm{N}_{2}$ matrix; (b) red line - spectrum obtained after irradiation at $\lambda=6910 \mathrm{~cm}^{-1}$ "minus" spectrum of the as-deposited $\mathrm{N}_{2}$ matrix. The most characteristic bands ascribed to conformer IITa (increasing upon both irradiations) are marked with a pink asterisk (*). Simulated IR difference spectra (at the B3LYP/6$311++\mathrm{G}(\mathrm{d}, \mathrm{p})$ level). The correspondence between the colors of the spectra and the conformers are indicated in the figure. In case of the photoproduced forms the factors used to scale intensities are also shown. The calculated frequencies scaled by 0.978 and 0.944 for the $v \mathrm{O}-\mathrm{H}$ stretching region.

found to increase of intensity. The theoretical spectrum corresponding to $(0.75 \mathrm{IITa}+0.25 \mathrm{ITc})$ minus $\mathrm{ICa}$ fits very well the experimental difference spectrum obtained by subtracting the spectrum obtained immediately after deposition of the matrix from the spectrum obtained after the $6910 \mathrm{~cm}^{-1}$ irradiation (Figure 4(b)).

The two performed NIR irradiation experiments undoubtedly demonstrate that the selective excitation of the first $\nu \mathrm{O}-\mathrm{H}$ overtone of ICa or ICc forms led to internal rotation of the $\mathrm{O}-\mathrm{H}$ group, converting these forms into their structurally related trans-COOH conformers: ITc and ITa respectively. Note that the energy of the exciting photons is of $\sim 55$ $\mathrm{kJ} \mathrm{mol}^{-1}$, which largely exceeds the energy required to overcome the internal rotation barriers converting the cis- $\mathrm{COOH}$ conformers into the trans ones (see Table IV).

The NIR irradiation experiments allowed not only the generation, trapping and vibrational characterization of two new conformers of PG (ITa and ITc), permitting to perform detailed band assignments for these two forms (see Tables S-V and S-VI in the supplementary material), ${ }^{61}$ but also provided the key information for undertaking the in depth assignment of the original bands due to ICa, ICc, and IITa forms, as they exhibited a distinct behavior along the two NIR irradiation experiments: the bands of ICc decreased upon irradiation at $6910 \mathrm{~cm}^{-1}$ and stay untouched upon irradiation at 6930 $\mathrm{cm}^{-1}$; the reverse behavior stands for the bands due to the ICa conformer; and the bands due to IITa increased as a result of both irradiations.

The NIR-induced production of IITa deserves some additional comments, since transformation of ICa or ICc into this form involves not only the flip of the light hydroxylic hydrogen atom but also the structural rearrangement of the heavy atom molecular skeleton (internal rotations around the $\mathrm{C}-\mathrm{C}_{\alpha}$ and $\mathrm{C}-\mathrm{N}$ bonds; see Figure 5). The increase of the IITa population can be easily noticed in Figure 4, where the characteristic IITa bands at 1360, 939, and $908 \mathrm{~cm}^{-1}$ (marked with a pink asterisk in the figure) clearly increase of intensity upon irradiation. The mechanism for production of IITa upon NIR irradiation of ICa or ICc cannot be directly addressed using stationary spectroscopy. Nevertheless, it seems probable that the reactant forms start undergoing the NIR-induced cis-totrans $\mathrm{COOH}$ conversion. Then, the resulting vibrationally excited species (let us call them ITc* and ITa*) may dissipate the excess of energy uniquely to the matrix (relaxing into ITc 

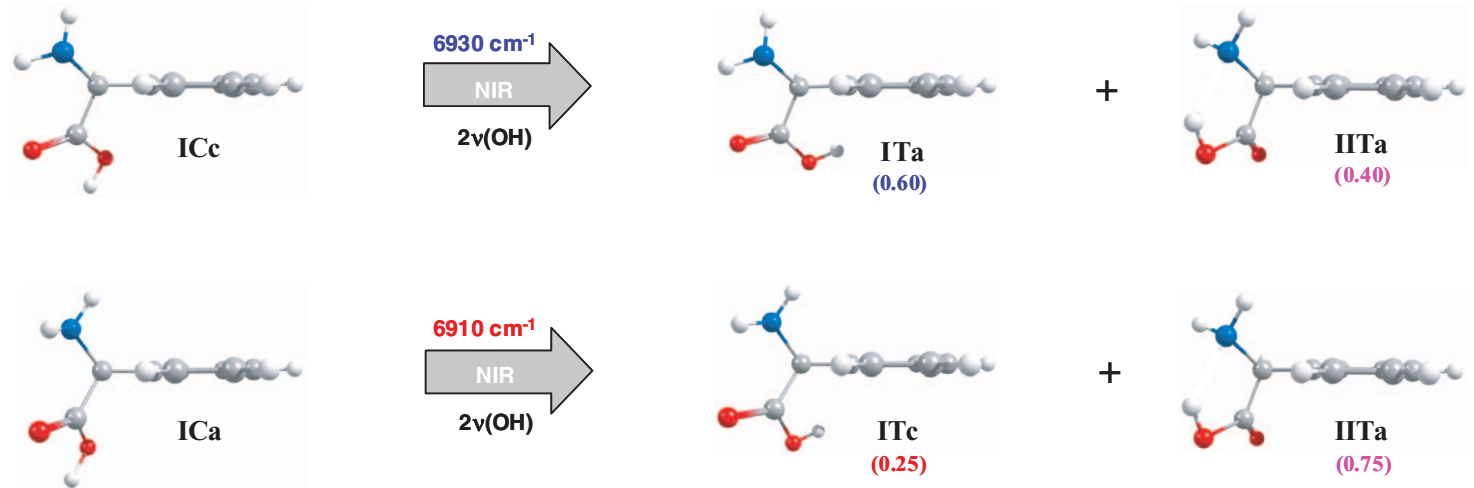

FIG. 5. Schematic representation of the observed selective near-IR induced conformational isomerizations of PG isolated in nitrogen matrix upon irradiation at $6930 \mathrm{~cm}^{-1}$ and $6910 \mathrm{~cm}^{-1}$. The numbers in parentheses represent the observed approximate branching ratios of production of the conformers (ITa and IITa or ITc and IITa).

and ITa) or use part of that energy to promote the rotation about the $\mathrm{C}-\mathrm{C}_{\alpha}$ and $\mathrm{C}-\mathrm{N}$ bonds (leading to IITa). The effectiveness of the two relaxation channels seems to be different in ITc* and ITa*, with the channel involving intramolecular coupling with the $\mathrm{C}-\mathrm{C}_{\alpha}$ and $\mathrm{C}-\mathrm{N}$ torsions (leading to IITa) being dominant for ITc*, while minor in the case of ITa*. This is reflected in the observed IITa/ITc $\sim 0.75: 0.25$ and IITa/ITa 0.4:0.6 branching ratios (see Figure 4). Such difference may be a consequence of the considerably larger energy of ITc compared to ITa (see Table II).

\section{E. Conformationally dependent UV-induced photolysis of PG monomer isolated in a xenon matrix}

In situ UV irradiation $(\lambda=255 \mathrm{~nm})$ of PG isolated in a xenon matrix resulted in photofragmentation of the compound and generation of different photoproducts. Upon irradiation, characteristic bands of $\mathrm{CO}_{2}\left(2337\right.$ and $\left.660 \mathrm{~cm}^{-1}\right)$ and $\mathrm{CO}\left(2132 \mathrm{~cm}^{-1}\right)$ appeared in the IR spectrum of the photolyzed matrix. These observations indicated that both decarboxylation and decarbonylation reactions were taking place. Together with these $\mathrm{CO}_{2}$ and $\mathrm{CO}$ characteristic bands (very easily observed because they appear in a clean spectral region), other bands, ascribable to $\mathrm{H}_{2} \mathrm{O}$, benzylamine, and benzonitrile, emerged in the spectrum of the irradiated matrix. The assignments of the most intense bands corresponding to the observed PG photoproducts are given in Table S-VIII in the supplementary material. ${ }^{61}$

Taking into account stoichiometric considerations and the different rates of production of $\mathrm{CO}_{2}$ and $\mathrm{CO}$ two independent photochemical routes could be identified. In the first one, $\mathrm{CO}_{2}$ is produced together with benzylamine, and in the second one, $\mathrm{CO}$ is produced together with $\mathrm{H}_{2} \mathrm{O}, \mathrm{H}_{2}$, and benzonitrile (see Figure 6). The growth of the benzonitrile characteristic $v \mathrm{C} \equiv \mathrm{N}$ band (at $2269 \mathrm{~cm}^{-1}$ ) with irradiation time was found to follow the same kinetic behavior of the $\mathrm{CO}$ band.

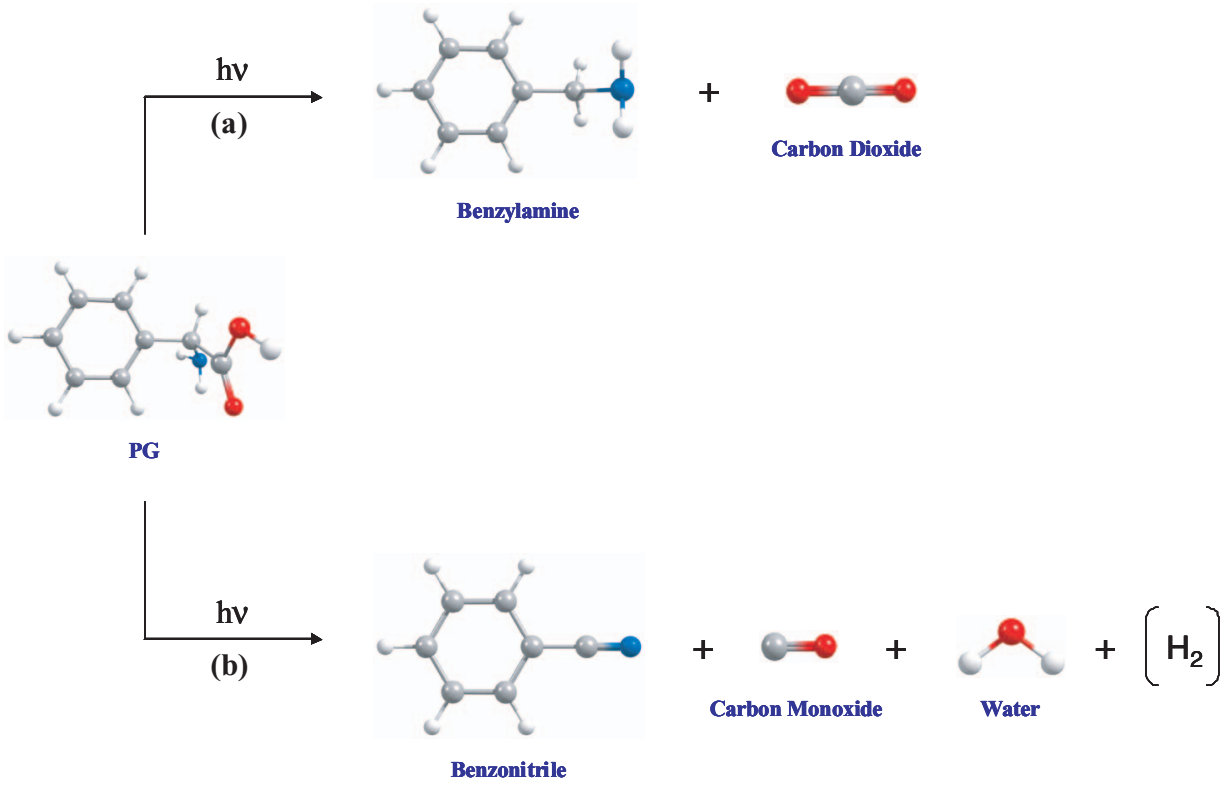

FIG. 6. Unimolecular photodecomposition channels observed in the UV $(\lambda=255 \mathrm{~nm})$ photochemistry of matrix isolated PG. According to the kinetic data pathway (a) is favored for the reactant species in a conformation with the carboxylic group in the cis configuration, while pathway (b) is favored for transcarboxylic group forms. 
One immediate additional observation was that the rate of consumption of the ICa and ICc conformers visibly differed from that of the IITa conformer. The bands due to conformers $\mathrm{ICc} / \mathrm{ICa}\left(\nu \mathrm{OH}\right.$, in the $3570-3540 \mathrm{~cm}^{-1}$ region) and IITa (bending modes in the 935-900 $\mathrm{cm}^{-1}$ range) were used together with the $\mathrm{CO}_{2}$ and $\mathrm{CO}$ bands at 2337 and 2132 $\mathrm{cm}^{-1}$ to perform kinetic studies. The integrated absorbances of these bands were normalized by the corresponding calculated infrared intensities and converted to relative abundances of these species in the matrix along the irradiation time. The resulting kinetic plots are shown in Figure 7, where one can see that the rate of consumption of the cis- $\mathrm{COOH}$ conformers ( $\mathrm{ICa}$ and $\mathrm{ICc}$ ) follows closely that of production of $\mathrm{CO}_{2}$, and the rate of consumption of IITa is similar to that of production of $\mathrm{CO}$ (and benzonitrile). This is then an interesting case where the initial conformation of the reactant determines the dominant photofragmentation pathway, with a $c i s-\mathrm{COOH}$ fragment favoring decarboxylation and a trans-COOH moiety favoring decarbonylation. A similar observation was reported previously for matrix-isolated serine. ${ }^{10}$

Note that instead of simple monoexponential functions (which very often failed to reproduce kinetic data for matrix isolated molecules - see, for example, Ref. 51), the kinetics curves obey the dispersive kinetics model $[\mathrm{n}(\mathbf{X})$ $=\mathrm{n}(\mathbf{X})_{t=0} \exp \left(-\mathrm{B} t^{\alpha}\right)$, where $\mathrm{k}(\mathrm{t})=\mathrm{B} t^{\alpha-1},(\mathrm{~B}, \alpha-$ constants; $\left.\mathrm{B} \equiv \alpha / \tau_{\text {disp }}^{\alpha}\right),{ }^{52,53}$ for decay of reactants, and similar growing curves for products], which applies when local microenvironments are different, so that the conversion is initially faster and then it slows down in comparison to the classical kinetics. In other words, quicker conversion occurs in some "better prepared" microenvironments of the matrix and then it is significantly slower for molecules in "worse prepared" microenvironments. Such behavior is typical of transformations of molecules embedded in inhomogeneous media. ${ }^{52,53}$ It is also interesting to note that in the dispersive-type kinetics, the lower the numerical value of $\alpha$, the greater the dispersivity of the process (the limit of classical kinetics corresponds to $\alpha=1$ ). Then, the value of $\alpha \approx 0.05$, obtained for the decay of the reactant species in the present case, suggests that the processes have a large dispersivity, i.e., the inhomogeneous character of the matrix cages are relevant in modulating the photochemical decomposition of PG. This might be correlated with the fact that in a matrix the diffusion of the products is quite limited or not allowed at all, and thus processes such as recombination of initially formed intermediates, subsequent complexation of the stable species, among others, became important. This might be considered a special type of "inhomogeneity," since all these processes may be influenced by the local matrix cage environment, increasing the dispersivity noticed in the kinetics curves.

In Figure 7, it can also be observed that the cis- $\mathrm{COOH}$ $\mathrm{ICa}$ and ICc conformers react faster than the trans-COOH IITa form. Note that the kinetic curves indicate that the time to reduce the population of $\mathrm{cis}$-carboxylic conformers to half of the original is $\sim 3 \mathrm{~min}$, while that corresponding to the decomposition of IITa is $\sim 20 \mathrm{~min}$, indicating that this latter process is considerably slower than the first one. If each of the processes occurred exclusively from one type of reactant (cis or trans-COOH), the curves shown in each panel of Figure 7
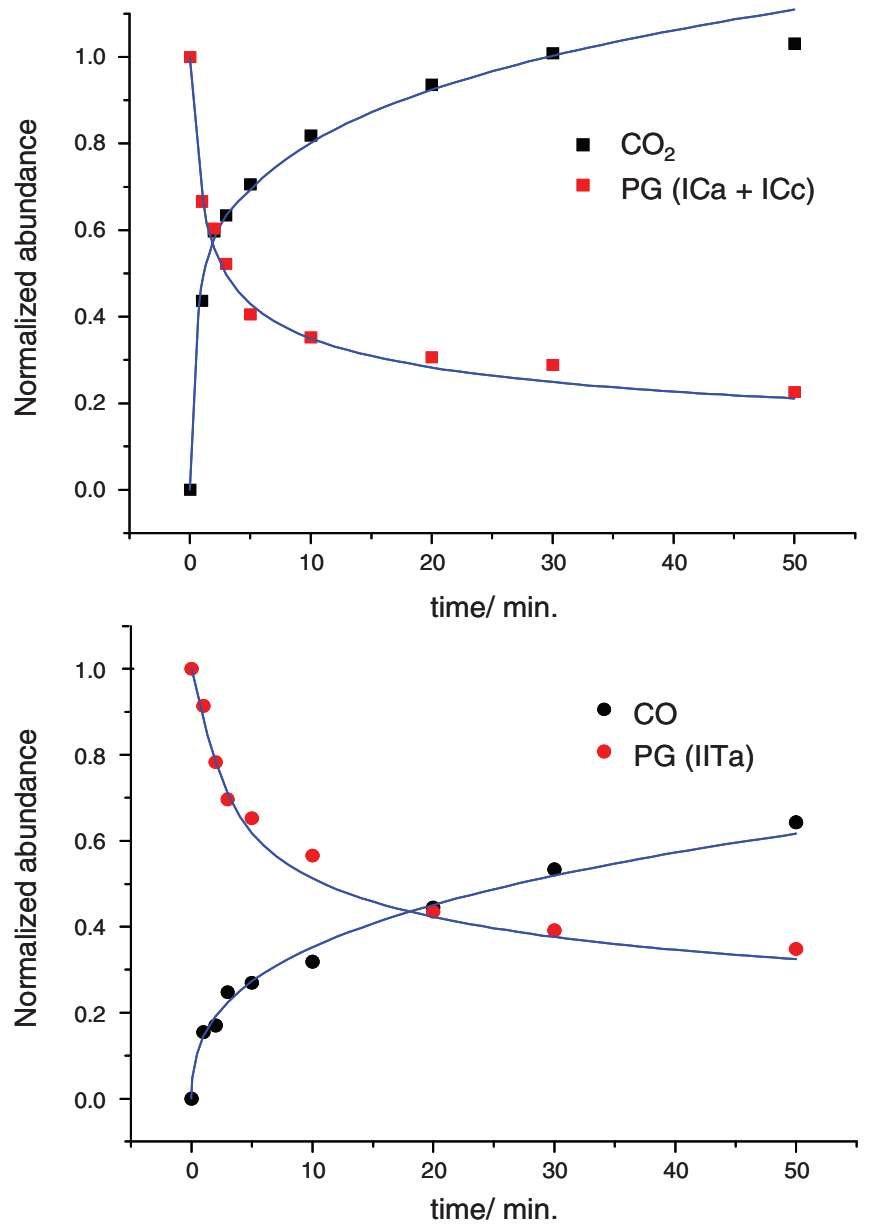

FIG. 7. Evolution of the relative abundances of the photoproduced $\mathrm{CO}_{2}$ and $\mathrm{CO}$ and reactant conformers of $\mathrm{PG}(\mathrm{ICa} / \mathrm{Cc}$ and IITa) with the time of irradiation $(\lambda=255 \mathrm{~nm})$. The curves were obtained from the integrated absorbances of bands due to $\mathrm{CO}\left(2132 \mathrm{~cm}^{-1}\right), \mathrm{CO}_{2}\left(2337 \mathrm{~cm}^{-1}\right), \mathrm{ICa} / \mathrm{ICc}$ forms of PG (3570-3540 $\mathrm{cm}^{-1}$ region) and PG conformer IITa $\left(935-900 \mathrm{~cm}^{-1}\right)$, weighted by the corresponding calculated IR intensities (for $\mathrm{cis}$ - $\mathrm{COOH}$ conformers, the sum of the IR intensities of the calculated $\nu \mathrm{OH}$ band for the two conformers, weighted by the corresponding populations was used), and then normalized to fit the reactant species to 1 . Solid lines represent the kinetics curves using the dispersive model (see text for details).

should cross exactly for an abundance of both reactants and products equal to 0.5 . The observed crossing points are indeed close to the expected value $(0.45$ and 0.6 , for decarbonylation and decarboxylation processes, respectively), pointing to a clear dominance of a single process for each type of conformer.

As found before for other carboxylic acids that undergo decarboxylation or decarbonylation reactions upon UV irradiation, ${ }^{54-59}$ the observed photochemical reactions in matrix-isolated PG shall involve radical intermediates resulting from $\alpha$-cleavages either of the $\mathrm{C}-\mathrm{C}_{\alpha}$ bond or $\mathrm{C}-\mathrm{O}$ bond. This indicates that, with all probability, the decomposition reactions take place mainly on the excited state surfaces rather than in the vibrationally excited ground state. For acetic acid, whose excited states surfaces have been extensively studied regarding photodecomposition dynamics, ${ }^{60}$ the transition states for the $\mathrm{C}-\mathrm{C}_{\alpha}$ bond cleavage (connected with decarboxylation) in the $S_{1}$ and $T_{1}$ surfaces were found to have geometries that can be correlated with different conformations 
of the carboxylic moiety: cis for $\mathrm{S}_{1}$ and trans for $\mathrm{T}_{1}$. If we assume that in PG a similar situation occurs, the decarboxylation reaction in this compound shall then be strongly preferred when started from cis-COOH conformers, once the $\mathrm{T}_{1} \leftarrow \mathrm{S}_{0}$ is a forbidden transition.

The observed faster kinetics of the decarboxylation process is probably also facilitated by the fact that in the two cis$\mathrm{COOH}$ conformers of PG the carboxylic moiety does not take part in any intramolecular hydrogen bond as proton donor. On the other hand, the decarbonylation reaction might be favored in the trans-COOH IITa conformer due to the involvement of its carboxylic group as proton donor in the strong $\mathrm{O}-\mathrm{H}^{\cdots} \mathrm{N}$ intramolecular hydrogen bond, which weakens the $\mathrm{C}-\mathrm{O}$ bond that must be broken in this reaction.

\section{CONCLUSIONS}

The main achievements of this investigation are stated as follows: (i) detailed characterization of the conformational landscape of PG at both DFT(B3LYP) and MP2 levels of approximation and determination of the dominant intramolecular interactions responsible for the relative energies of the various conformers; (ii) complete theoretical vibrational characterization of the different conformers of the compound; (iii) prediction of the equilibrium populations of the conformers of PG in the gas phase, based on the theoretical results and on the spectra of the as-deposited matrices of the compound; (iv) detailed assignment of the IR spectra of 5 conformers of the studied compound isolated in cryogenic matrices, including three conformers observed for the first time in the present study (ICc, ITa, ITc); (v) generation of two high-energy conformers of PG (ITa, ITc) by narrowband NIR-selective pumping of conformers ICa and ICc in nitrogen matrix; (vi) proposition of a mechanism for the observed partial transformation of the ICa and ICc into IITa, which was observed to take place concomitantly with the generation of ITa and ITc forms upon NIR-irradiation in nitrogen matrix; and (vii) observation of two conformational selective photofragmentation processes (decarboxylation and decarbonylation) upon UV irradiation $(\lambda=255 \mathrm{~nm})$ of xenon matrices, and proposition of a possible mechanism, consistent with the observations.

Altogether, these results allowed to considerably improving the understanding of the structural, vibrational, and photochemical properties of PG.

\section{ACKNOWLEDGMENTS}

This work was supported by Fundação para a Ciência $e$ a Tecnologia (FCT, Project the project PestOE/QUI/UI0313/2014, also supported by QREN-COMPETE and the European Union). A.B. acknowledges FCT for the award of a Post-Doctoral Grant (SFRH/BPD/66154/2009). A.G.-Z. is member of the Research Career of CONICET (National Research Council, Argentina).

${ }^{1}$ A. Boto, J. A. Gallardo, R. Hernández, F. Ledo, A. Muñoz, J. R. Murguía, M. Menacho-Márquez, A. Orjales, and C. J. Saavedra, Bioorg. Med. Chem. Lett. 16, 6073-6077 (2006).

${ }^{2}$ M. M. Ilczyszyn, T. Lis, and M. Wierzejewska, J. Mol. Struct. 937, 2-9 (2009).
${ }^{3}$ R. M. Williams, "Synthesis of optically active $\alpha$-amino acids," Organic Chemistry Series (Pergamon Press, Oxford, 1989), Chap. 7.

${ }^{4}$ L. Wang and P. G. Schultz, Angew. Chem., Int. Ed. 44, 34-66 (2005).

${ }^{5} \mathrm{~N}$. Voyer and J. Lamothe, Tetrahedron 51, 9241-9284 (1995).

${ }^{6}$ S. G. Stepanian, I. D. Reva, E. D. Radchenko, M. T. S. Rosado, M. L. T. S. Duarte, R. Fausto, and L. Adamowicz, J. Phys. Chem. A 102, 1041-1054 (1998).

${ }^{7}$ S. G. Stepanian, I. D. Reva, E. D. Radchenko, and L. Adamowicz, J. Phys. Chem. A 102, 4623-4629 (1998).

${ }^{8}$ S. G. Stepanian, I. D. Reva, E. D. Radchenko, and L. Adamowicz, J. Phys. Chem. A 103, 4404-4412 (1999).

${ }^{9}$ A. Gómez-Zavaglia, I. D. Reva, and R. Fausto, Phys. Chem. Chem. Phys. 5, 41-51 (2003).

${ }^{10}$ S. Jarmelo and R. Fausto, J. Mol. Struct. 786, 175-181 (2006).

${ }^{11}$ A. Kaczor, I. D. Reva, L. M. Proniewicz, and R. Fausto, J. Phys. Chem. A 110, 2360-2370 (2006).

${ }^{12}$ C. M. Nunes, L. Lapinski, R. Fausto, and I. Reva, J. Chem. Phys. 138, 125101 (2013).

${ }^{13}$ N. Kuş, A. Sharma, I. Peña, M. C. Bermúdez, C. Cabezas, J. L. Alonso, and R. Fausto, J. Chem. Phys. 138, 144305 (2013).

${ }^{14}$ M. E. Sanz, V. Cortijo, W. Caminati, J. C. López, and J. L. Alonso, Chem. Eur. J. 12, 2564-2570 (2006).

${ }^{15}$ H. M. Kim, K. Y. Han, J. Park, S. K. Kim, and Z. H. Kim, J. Chem. Phys. 128, 184313 (2008).

${ }^{16}$ L. J. Mittal, J. P. Mittal, and E. Hayon, J. Phys. Chem. 77, 1620-1623 (1973).

${ }^{17}$ H. M. Kim, K. Y. Han, J. Park, G.-S. Kim, and S. K. Kim, J. Chem. Phys. 128, 041104 (2008).

${ }^{18}$ A. Borba, A. Gómez-Zavaglia, L. Lapinski, and R. Fausto, Phys. Chem. Chem. Phys. 6, 2101-2108 (2004).

${ }^{19}$ A. Borba, A. Gómez-Zavaglia, L. Lapinski, and R. Fausto, Vib. Spectrosc. 36, 79-88 (2004).

${ }^{20}$ A. Borba, A. Gómez-Zavaglia, P. Simões, and R. Fausto, Spectrochim. Acta, Part A 61, 1461-1470 (2005).

${ }^{21}$ A. Borba, A. Gómez-Zavaglia, P. Simões, and R. Fausto, J. Phys. Chem. A 109, 3578-3586 (2005).

${ }^{22}$ R. Fausto, L. Khriachtchev, and P. Hamm, "Conformational changes in cryogenic matrices," in Physics and Chemistry at Low Temperatures, edited by L. Khriachtchev (Pan Stanford, 2010), Chap. 3, p. 51.

${ }^{23}$ I. D. Reva, S. G. Stepanian, L. Adamowicz, and R. Fausto, Chem. Phys. Lett. 374, 631-638 (2003).

${ }^{24}$ A. Borba, A. Gómez-Zavaglia, and R. Fausto, J. Mol. Struct. 794, 196-203 (2006).

${ }^{25}$ A. Borba, A. Gómez-Zavaglia, and R. Fausto, J. Phys. Chem. A 117, 704717 (2013).

${ }^{26}$ M. J. Frisch, G. W. Trucks, H. B. Schlegel et al., GAUSSIAN 09, Revision C. 01, Gaussian, Inc., Wallingford CT, 2010.

${ }^{27}$ A. D. Becke, Phys. Rev. A 38, 3098 (1988).

${ }^{28}$ C. T. Lee, W. T. Yang, and R. G. Parr, Phys. Rev. B 37, 785-789 (1988).

${ }^{29}$ S. H. Vosko, L. Wilk, and M. Nusair, Can. J. Phys. 58, 1200-1211 (1980).

${ }^{30}$ C. Moller and M. S. Plesset, Phys. Rev. 46, 618-622 (1934).

${ }^{31}$ M. J. Frisch, M. Head-Gordon, and J. A. Pople, Chem. Phys. Lett. 166, 281-289 (1990).

${ }^{32}$ P. Császár and P. Pulay, J. Mol. Struct. 114, 31-34 (1984).

${ }^{33}$ C. Peng and H. Schlegel, Isr. J. Chem. 33, 449-454 (1993).

${ }^{34}$ A. Gómez-Zavaglia, A. Ismael, L. I. L. Cabral, A. Kaczor, J. A. Paixão, R. Fausto, and M. L. S. Cristiano, J. Mol. Struct. 1003, 103-110 (2011).

${ }^{35}$ S. Breda, I. Reva, and R. Fausto, J. Mol. Struct. 887, 75-86 (2008).

${ }^{36}$ K. K. Irikura, Program SYNSPEC, National Institute of Standards and Technology, Gaithersburg, USA, 2002.

${ }^{37}$ G. Keresztury and G. Jalsovszky, J. Mol. Struct. 10, 304-305 (1971).

${ }^{38}$ H. Rostkowska, L. Lapinski, and M. J. Nowak, Vib. Spectrosc. 49, 43-51 (2009).

${ }^{39}$ P. Pulay, G. Fogarasi, F. Pang, and J. E. Boggs, J. Am. Chem. Soc. 101, 2550-2560 (1979).

${ }^{40}$ R. Fausto, P. R. Carey, and P. J. Tonge, J. Chem. Soc., Faraday Trans. 90, 3491-3503 (1994).

${ }^{41}$ A. Gomez-Zavaglia and R. Fausto, Vib. Spectrosc. 33, 105-126 (2003).

${ }^{42}$ M. Rozenberg, G. Shoham, I. D. Reva, and R. Fausto, Spectrochim. Acta, Part A 60, 463-470 (2004).

${ }^{43}$ S. C. S. Bugalho, E. M. S. Maçôas, M. L. S. Cristiano, and R. Fausto, Phys. Chem. Chem. Phys. 3, 3541-3547 (2001). 
${ }^{44}$ S. Lopes, A. V. Domanskaya, R. Fausto, M. Räsänen, and L. Khriachtchev, J. Chem. Phys. 133, 144507 (2010).

${ }^{45}$ M. Pettersson, E. M. S. Maçôas, L. Kriachtchev, R. Fausto, and M. Rasänen, J. Am. Chem. Soc. 125, 4058-4059 (2003).

${ }^{46}$ M. Pettersson, E. M. S. Maçôas, L. Khriachtchev, J. Lundell, and M. Räsänen, R. Fausto, J. Chem. Phys. 117, 9095-9098 (2002).

${ }^{47}$ E. M. S. Maçôas, L. Khriachtchev, M. Pettersson, R. Fausto, and M. Räsänen, J. Am. Chem. Soc. 125, 16188-16189 (2003).

${ }^{48}$ L. Lapinski, I. Reva, H. Rostkowska, A. Halasa, R. Fausto, and M. J. Nowak, J. Phys. Chem. A 117, 5251-5259 (2013).

${ }^{49}$ G. Bazsó, G. Magyarfalvi, and G. Tarczay, J. Phys. Chem. A 116, 1053910547 (2012).

${ }^{50}$ G. Bazsó, E. Najbauer, G. Magyarfalvi, and G. Tarczay, J. Phys. Chem. A 117, 1952-1962 (2013).

${ }^{51}$ I. Reva, M. J. Nowak, L. Lapinski, and R. Fausto, J. Chem. Phys. 136, 064511 (2012).

${ }^{52} \mathrm{~W}$. Siebrand and T. A. Wildman, Acc. Chem. Res. 19, 238-243 (1986).

${ }^{53}$ A. Plonka, Dispersive Kinetics (Kluwer Academic, Dordrecht, The Netherlands, 2001)

${ }^{54}$ D. Tevault, M. Lin, M. Umstead, and R. Smardzewski, Int. J. Chem. Kinet. 11, 445-449 (1979).

${ }^{55}$ R. Fausto, E. M. S. Maçôas, and A. Kulbida, J. Mol. Struct. 480-481, 8399 (1999).

${ }^{56}$ E. M. S. Maçôas, L. Khriachtchev, R. Fausto, and M. Räsänen, J. Phys. Chem. A 108, 3380-3389 (2004).
${ }^{57}$ S. S. Hunnicutt, L. D. Wait, and J. A. Guest, J. Phys. Chem. 95, 562-570 (1991).

${ }^{58}$ D. R. Peterman, R. G. Daniel, R. J. Horwitz, and J. A. Guest, Chem. Phys. Lett. 236, 564-570 (1995).

${ }^{59}$ P. D. Naik, H. P. Hupadhyaya, A. Kumar, A. V. Sapre, and J. P. Mittal, Chem. Phys. Lett. 340, 116-122 (2001).

${ }^{60}$ W. H. Fang, R.-Z. Liu, X. Zheng, and D. Phillips, J. Org. Chem. 67, 84078415 (2002).

${ }^{61}$ See supplementary material at http://dx.doi.org/10.1063/1.4897526 for Table S-I, with the definition of the internal coordinates used in the normal modes analysis of the conformers of phenylglycine; Tables S-II-S-VII, with experimental FTIR spectra (argon, nitrogen, and xenon matrices) and calculated [B3LYP/6-311++G(d,p) level] vibrational frequencies, intensities, and potential energy distributions for observed PG conformers; Table S-VIII, with experimental and calculated [B3LYP/6-311++G(d,p)] vibrational frequencies and calculated IR intensities for the observed photoproducts of PG monomer isolated in xenon matrix; Figure S1, with the relevant potential energy profiles for the interconversion between the $c i s-\mathrm{COOH}$ conformers of PG; Figure S2, with the relevant potential energy profiles for the trans-cis interconversion in PG; Figure S3, experimental near-IR spectrum of monomeric PG isolated in nitrogen matrix at $16 \mathrm{~K}$, showing the $2 v(\mathrm{OH})$ region of conformer ICa and ICc. The color bars indicate the positions where the laser output was tuned (blue $=6930 \mathrm{~cm}^{-1}$ and red $=6910 \mathrm{~cm}^{-1}$ ). Equilibrium Cartesian coordinates and vibrational spectra calculated at the MP2/6-311++G(d,p) and DFT/B3LYP/6-311++G(d,p) levels are also provided (Computational Data). 